Prepared for the U.S. Department of Energy

under Contract DE-AC05-76RL01830

\title{
Interval Data Analysis with the Energy Charting and Metrics Tool (ECAM)
}

\section{DJ Taasevigen \\ S Katipamula \\ W Koran}

July 2011

Pacific Northwest

NATIONAL LABORATORY

Proudly Operated by Battelle Since 1965 


\section{DISCLAIMER}

This report was prepared as an account of work sponsored by an agency of the United States Government. Neither the United States Government nor any agency thereof, nor Battelle Memorial Institute, nor any of their employees, makes any warranty, express or implied, or assumes any legal liability or responsibility for the accuracy, completeness, or usefulness of any information, apparatus, product, or process disclosed, or represents that its use would not infringe privately owned rights. Reference herein to any specific commercial product, process, or service by trade name, trademark, manufacturer, or otherwise does not necessarily constitute or imply its endorsement, recommendation, or favoring by the United States Government or any agency thereof; or Battelle Memorial Institute. The views and opinions of authors expressed herein do not necessarily state or reflect those of the United States Government or any agency thereol:

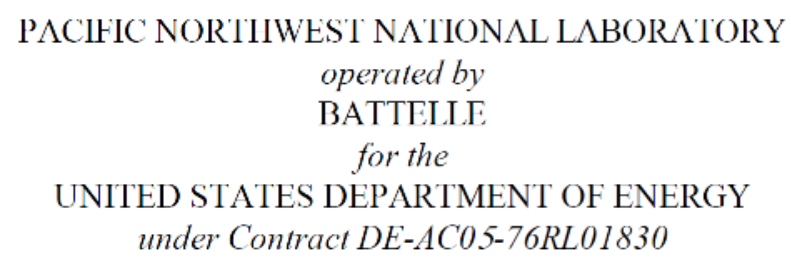

Printed in the United States of America

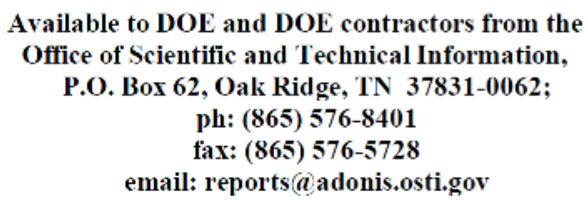

Available to the public from the National Technical Information Service,

U.S. Department of Commerce, 5285 Port Royal Rd., Springfield, VA 22161

ph: (800) 553-6847

fax: $(703) 605-6900$

email: orders@ntis.fedworld.gov

online ordering: http://www.ntis.gov/ordering.htm

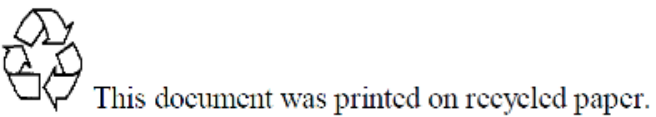

(9/2003) 


\title{
Interval Data Analysis with the Energy Charting and Metrics Tool (ECAM)
}

\author{
D Taasevigen \\ S Katipamula \\ W Koran
}

July 7, 2011

Prepared for

U.S. Department of Energy

under Contract DE-AC05-76RL01830

PNNL-20495

Pacific Northwest National Laboratory

Richland, Washington 99352

This report was prepared as an account of work sponsored by an agency of the United States Government. Neither the United States Government nor any agency thereof, nor Battelle Memorial Institute, nor any of their employees, makes any warranty, express or implied, or assumes any legal liability or responsibility for the accuracy, completeness, or usefulness of any information, apparatus, product, or process disclosed, or represents that its use would not infringe privately owned rights. Reference herein to any specific commercial product, process, or service by trade name, trademark, manufacturer, or otherwise does not necessarily constitute or imply its endorsement, recommendation, or favoring by the United States Government or any agency thereof, or Battelle Memorial Institute. The views and opinions of authors expressed herein do not necessarily state or reflect those of the United States Government or any agency thereof. 



\section{Acknowledgement}

The authors acknowledge the Building Technologies Program within the U.S. Department of Energy Office of Energy Efficiency and Renewable Energy for supporting preparation of this report. The authors also acknowledge the support and encouragement from Michael Baechler, Program Manager at PNNL and Subid Wagley, Technology Development Manager at DOE.

ECAM was originally developed, and has now been updated to v2.0, by William Koran of Quantum Energy Services \& Technologies. Additional support for v2.0 development, and coordination of testing, was provided by Nick Bengtson and Eliot Crowe of Portland Energy Conservation, Inc. The California Commissioning Collaborative (CCC) managed the development of ECAM.

The original development of ECAM was co-funded by the Northwest Energy Efficiency Alliance, New Buildings Institute, and the California Energy Commission. The update to v2.0 was primarily funded through the California Energy Commission's Public Interest Energy Research (PIER) program, with additional funding from the CCC and the Northwest Energy Efficiency Alliance. Version 2.0 also benefits from the incorporation of charting and functionality developed by the Pacific Northwest National Laboratory for their "Building Re-Tuning" Program, which was funded by Washington State.

A number of individuals provided useful feedback on ECAM v2.0 based on beta testing: Danny Taasevigen and Srinivas Katipamula, PNNL; Amber Buhl and Ben Cartwright, PECI; and Brad Acker, University of Idaho. 


\section{Contents}

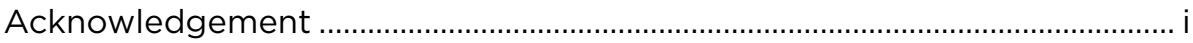

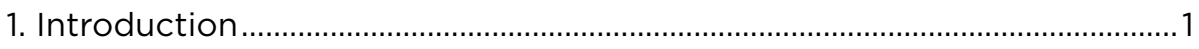

2. Energy Charting and Metrics Tool (ECAM) ..................................................

3. Menu Items for Preprocessing of Data........................................................... 2

4. Features: Creating Time Series Charts …………........................................... 9

5. Load Profile as Box Plots ..................................................................................15

6. Scatter Charts................................................................................................15

7. Interval Metered Data Analysis.......................................................................... 18

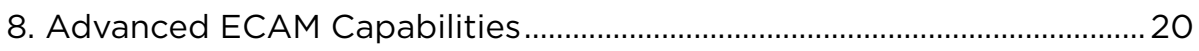

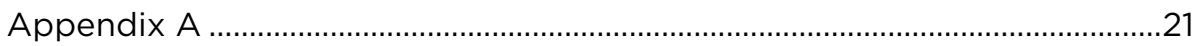

\section{Figures}

Figure 1: Utility Company Meter Data Example.

Figure 2: ECAM Utilities Selection to Convert Table

Format to ECAM List Format ............................................................

Figure 3: Input the Data Range for Conversion ............................................. 2

Figure 4: Formatted Utility Company Data .................................................... 2

Figure 5: Sample Raw Data File (.csV or .xls format).................................. 3

Figure 6: Select Data under the ECAM Dropdown Menu.............................. 3

Figure 7: Time Stamp Definition in ECAM................................................. 3

Figure 8: Input the Data Range .....................................................................

Figure 9: Is Ambient Temperature Included ................................................... 4

Figure 10: Processed "raw data" in ECAM .................................................... 4

Figure 11: Building Information after Selecting

"Definition of Points"............................................................................. 5

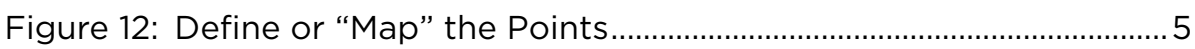

Figure 13: Example of OAT being Mapped in ECAM ………….........................5

Figure 14: Example of Whole Building Consumption being Mapped in ECAM

Figure 15: Creating Schedules in ECAM ............................................................. 7

Figure 16: Second Tab for Adding Schedules (Week Schedules)................. 7

Figure 17: Annual Schedules Input Tab.......................................................... 7

Figure 18: Entering a Date When an Energy Project Started for Comparison of Pre/Post.

Figure 19: Entering a Date When an Energy Project Finished for Comparison of Pre/Post 8

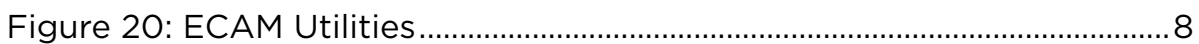

Figure 21: Time Series Charts ......................................................................... 9

Figure 22: Point Selection for the Point(s) History Chart..............................9

Figure 23: Example of Choosing the Header or Point Name for the Point(s) History Chart.

Figure 24: Point(s) History Chart Created in ECAM After Making Appropriate Data Selection.

Figure 25: Using the Pivot Table to Modify Data Selection on the Point History Chart 
Figures (continued)

Figure 26: Point History Chart Filtered to Only Show

November 2008.

Figure 27: Using the Pivot Table to Select Specific Days

to be Displayed on the Point History Chart

Figure 28: Using the Pivot Table to Only Select 1 Week of Data

on the Point History Chart

Figure 29: Load Profile by Day Type

Figure 30: Load Profile by Month-Year............................................................12

Figure 31: Load Profile by Year .................................................................

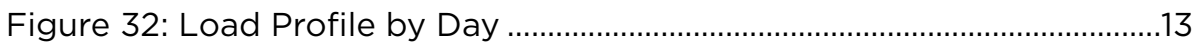

Figure 33: Load Profile by Day Filtered to January 2009............................13

Figure 34: 3d Load Profile Created from the Load Profile

by Day Chart

Figure 35: Energy Colors Chart Created from the Load Profile

by Day Chart 14

Figure 36: Load Profile Calendar for January 2009....................................... 14

Figure 37 Load Profile as Box Plots Chart in ECAM......................................15

Figure 38: Point Selection Window for a Scatter Chart by Occupancy ...15

Figure 39: Scatter Chart by Occupancy With Errors.

Figure 40: Removing the "Blank" Values from the OAT

to get a Useful Chart

Figure 41: Correct Scatter Chart in ECAM with No Schedule

in Place for Occupancy..... 16

Figure 42: Scatter Chart by Occupancy in ECAM

with a Schedule Input. 16

Figure 43: Scatter Chart Aggregated to Ppot Trends 16

Figure 44: Creating a Scatter Chart by Date Range .17

Figure 45: Point Selection for Scatter Chart by Date Range ........................17

Figure 46: Incorrect Scatter Chart by Date Range ..........................................17

Figure 47: Correct Scatter Chart by Date Range ..............................................17

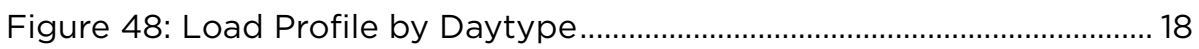

Figure 49: Typical Load Profile by Daytype for Hospital or Hotel............. 18

Figure 50: Typical Office Building Load Profile by Daytype........................ 19

Figure 51: Office Building that is Well Controlled and Operated............... 19

Figure 52: Office Building Load Profile Comparison Before and After Retrofit or Retro-Commissioning 19

Figure 53: Matrix Charts Dropdown Menu

Figure 54: ECAM Utilities to Copy Worksheet and Update ECAM Chart Source 20

Figure 55: Point History Charts Side by Side via the Matrix Selected Charts Option in ECAM. 


\section{Interval Data Analysis with the Energy Charting and Metrics Tool (ECAM)}

\section{Introduction}

A number of studies have shown that commercial buildings in the U.S. waste as much as $10 \%$ to $30 \%$ of the energy they use. Analysis of whole building interval data $^{1}$ can be an effective way to identify and improve building operations, and ultimately reduce operating cost. Simple automated charts in a spreadsheet can be used for analyzing the data to identify savings opportunities. In addition to the interval data, if outdoor dry-bulb temperature is available, additional analysis of the data are possible. A tool recently developed by the California Energy Commission (CEC) is well suited for such analysis. This document provides in-depth instructions and examples for creating useful information from the interval data using that tool.

\section{Energy Charting and Metrics Tool (ECAM)}

The ECAM tool was developed to facilitate the examination of energy information from buildings, while reducing the time spent analyzing interval meter data. The tool makes extensive use of Excel ${ }^{\circledR}$ Pivot Tables to facilitate summarization and filtering of the data. In addition to supporting normal Pivot Tables and Pivot Charts, it also automates creation of scatter charts based on Pivot Table data. Some key features of ECAM include: creation of schedules and day-type information to time series data; filtering data from months, years, days, daytype, day of week, day of month, occupancy, temperature binned weather data (if temperature data is included in addition to the interval data), pre/post comparisons after retrofits or retro-commissioning; normalizing data and creating metrics based on consumption or equipment; and the creation of various load profiles or scatter charts for data selected by the user. ECAM is an add-on for Microsoft Excel and is compatible with 2003, 2007, and 2010. See Appendix A for installation instructions.

Much of the charting capabilities described in the previous paragraph can be done with just the time series interval data. However, if outdoor air temperature (OAT) is available, the tool provides additional analysis capabilities. The interval data can either be average power consumption ( $\mathrm{kW}$ ) or energy consumption (kWh). If the energy/power consumption data and OAT data are not in a single file, they have to be merged into a single file with a single time stamp. The merging of the data can be done using the Universal Translator (available at www.utonline.org).

Utilizing ECAM in Microsoft Excel, a series of plots can be created to analyze and monitor a building's performance over time, gain knowledge of how the building performs over time, and make adjustments on the building's systems to improve efficiency and reduce energy costs. 


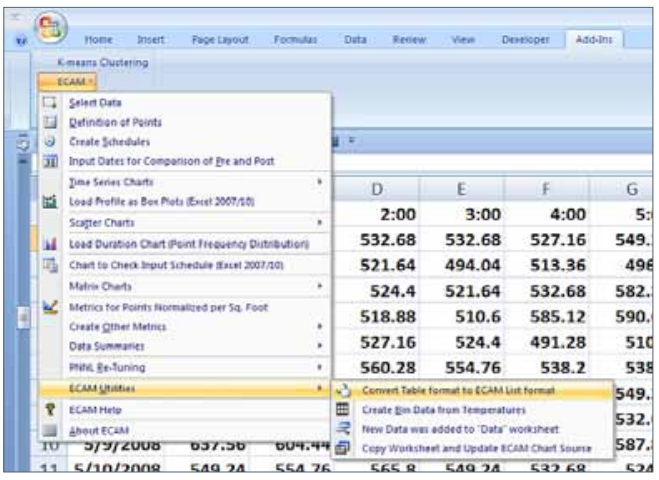

Figure 2: ECAM Utilities Selection to Convert Table Format to ECAM List Format

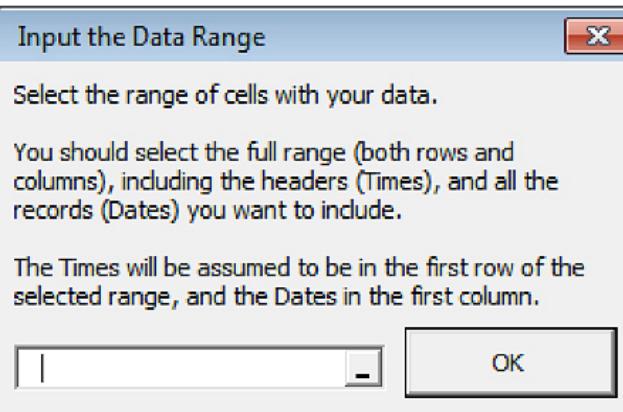

Figure 3: Input the Data Range for Conversion

\section{Menu Items for Preprocessing of Data}

In this section the various menu items for preprocessing the interval data are described.

\subsection{Utility Company Data}

Many utility companies provide data with a consistent format, and ECAM has the ability to convert that data and generate charts. Figure 1 below shows an example of utility data that is convertible in ECA

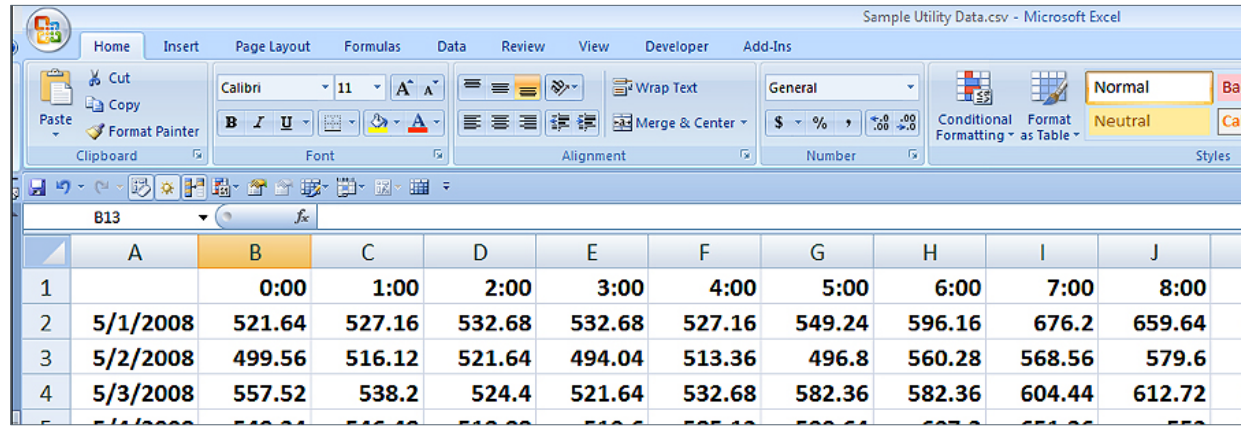

Figure 1: Utility Company Meter Data Example

The data above has the time stamp split into date (column A) and time (row 1). This particular set is in 1-hour increments, and the interior data is metered $\mathrm{kWh}$ data. Before running the ECAM utility to convert this data, you must make sure there is a header above the dates or you will get an error message when trying to convert the data. The word "Date" must appear in cell A1. Now, under the Add-Ins tab in Excel, click on the ECAM dropdown menu and select "ECAM Utilities" and "Convert Table format to ECAM List format," as shown in Figure 2. This selection will bring up the dialogue box shown in Figure 3, to input the data range.

Click on the "Date" cell and highlight all of the data by dragging the mouse to the far right, and then bottom and then click OK. ECAM will format the data and place it in a new sheet in the same workbook and call it "Data." Figure 4 below shows the final result after running the ECAM utility. Save the file as an ".csv" or ".xls" file. This data is now ready to be processed in ECAM, and will be discussed in the next section with the first step, "select data." If the raw interval data is already in the format shown in Figure 4, the conversion steps illustrated in Figure 2 and Figure 3 can be skipped.

\begin{tabular}{|c|c|c|c|}
\hline \multicolumn{4}{|c|}{ (두연) } \\
\hline & \multirow{2}{*}{\multicolumn{2}{|c|}{$\begin{array}{l}\text { \& Cut } \\
\text { - }{ }^{-j} \text { Copy } \\
\text { Format Painter }\end{array}$}} & Calibri \\
\hline & & & $\begin{array}{lll}\mathbf{B} & I & \underline{\mathrm{U}} \\
\end{array}$ \\
\hline & \multicolumn{2}{|c|}{ Clipboard } & \\
\hline 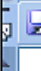 & 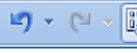 & 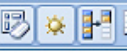 & 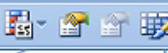 \\
\hline \multicolumn{3}{|c|}{ N10 } & $f_{x}$ \\
\hline 4 & A & B & C \\
\hline 1 & Date & Time & Value \\
\hline 2 & $5 / 10 / 2008$ & 23:00 & 471.96 \\
\hline 3 & $5 / 10 / 2008$ & 22:00 & 485.76 \\
\hline 4 & $5 / 10 / 2008$ & 21:00 & 469.2 \\
\hline 5 & $5 / 10 / 2008$ & 20:00 & 483 \\
\hline 6 & $5 / 10 / 2008$ & 19:00 & 469.2 \\
\hline 7 & $5 / 10 / 2008$ & 18:00 & 507.84 \\
\hline 8 & $5 / 10 / 2008$ & 17:00 & 485.76 \\
\hline 9 & $5 / 10 / 2008$ & 16:00 & 480.24 \\
\hline 10 & $5 / 10 / 2008$ & $15: 00$ & 538.2 \\
\hline
\end{tabular}

Figure 4: Formatted Utility Company Data 


\subsection{Select Data}

The first item under the ECAM dropdown menu is "select data." Before selecting the data, make sure the data file is either a ".csv" or ".xls" file type and is open. Make sure the first column is the time stamp for the data and that the header for the time stamp is located in row 1, column 1 in the Excel workbook. The time stamp should have the date and time, and ECAM gives the option of having the time stamp be in one or two columns, so it is OK to have just the date in column 1 and the time in column 2 , or both in column 1 . There should only be two other columns of data: the whole building electrical load, and the outdoor air temperature. See Figure 5 below for a typical raw data file with both consumption and OAT data. If the data was converted from utility metered data, as in Figure 4, then the data file would have the first two columns as the time stamp and a third column as the whole building electrical load. The OAT will not be in this file, but could be added using the Universal Translator tool. For all of the following charts, we will assume the data has the date/time in one column, the whole building electrical consumption in the next, and the OAT in the last column.

ECAM will only accept specific date and time formats. One of them that is accepted and shown above is $\mathrm{mm} / \mathrm{dd} / \mathrm{yyyy} \mathrm{hh} / \mathrm{mm}$. If you try and run ECAM and get an error related to the time stamp, try changing the format to the acceptable time stamp.

Once the raw data has been prepared and opened like in Figure 5, choose "select data" from the ECAM dropdown menu as shown in Figure 6. There will be a prompt that follows (Figure 7) asking if the time stamps are in one or two columns. Make the appropriate selection and click OK.

The next window (Figure 8) that will open will ask you to select the range of cells with the data. All of the data should be selected, including the headers or point names. There are multiple options listed below for selecting the data, but the critical point is to start at the upper left cell of the worksheet.

To select data:

1. When prompted, select the first (upper-left) cell in the data.

2. Hold down the Ctrl and Shift keys, and strike the right arrow and then the down arrow.

3. This should select all continuous data.

4. Click OK.

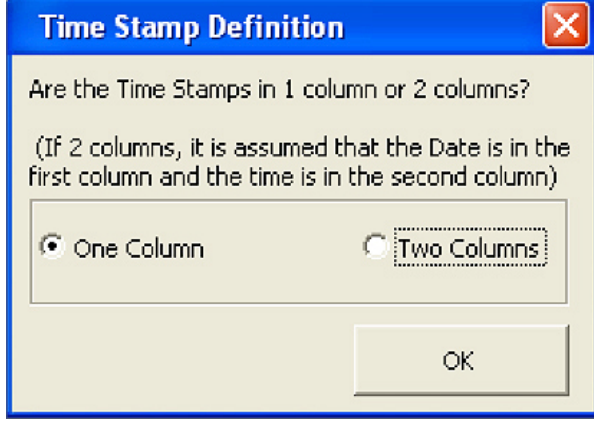

Figure 7: Time Stamp Definition in ECAM

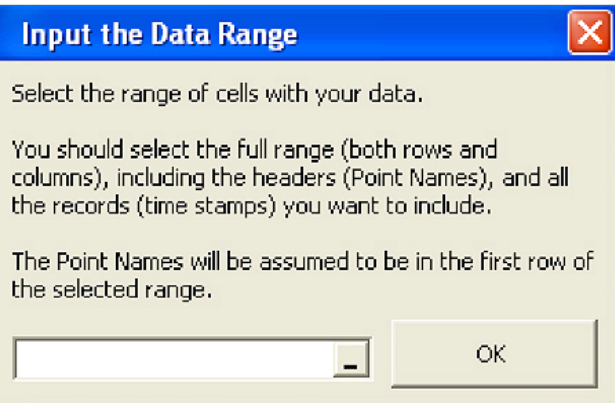

Figure 8: Input the Data Range

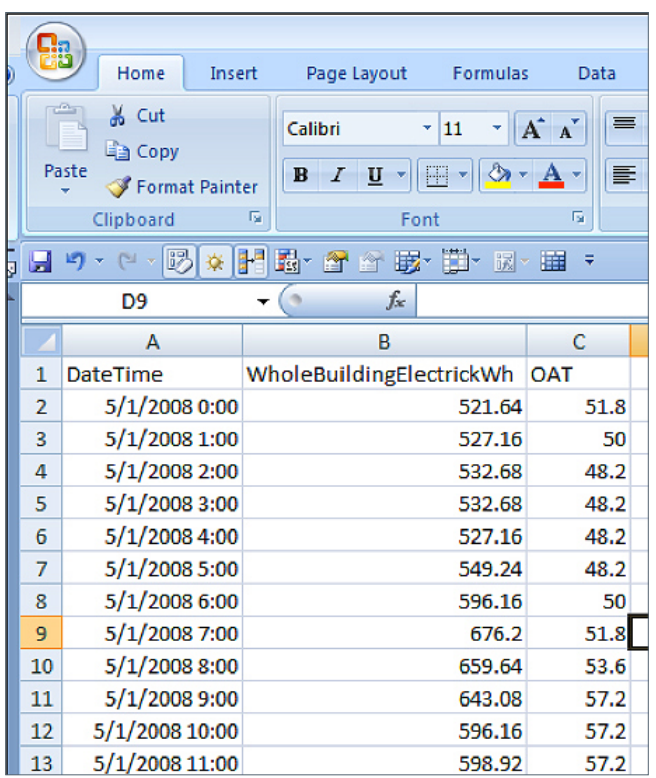

Figure 5: Sample Raw Data File (.csv or .xls format)

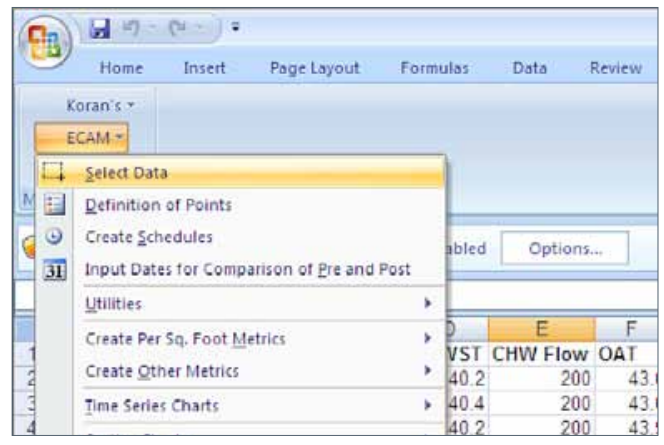

Figure 6: Select Data under the ECAM Dropdown Menu 


\section{Ambient Temperature}

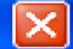

Is Ambient Temperature data included?
(* Yes
S. No

Which column has the Ambient Temperatures?

AllData!\$F\$1| OK

Figure 9: Is Ambient Temperature Included
If there are time stamps or data that need to be excluded, it If there are time stamps or data that need to be excluded, it may be easier to select a subset of data by using the mouse. Select the first cell of desired data, scroll until the last cell of desired data is visible, hold down the Shift key and select the last cell, and click OK. Of course, it is also possible to manually type in the data range as well in the space provided in Figure 8.

Once the data has been selected, one last window (Figure 9) will come up asking if ambient temperature data is included. After selecting "Yes," you will be asked which column has the ambient temperatures. You can click anywhere in the temperature column, and ECAM will accept it.

After selecting the temperature column and clicking OK, the processed data will appear in a new workbook as shown in Figure 10. Before doing anything else with the new file, save it as an Excel macro-enabled workbook.

\begin{tabular}{|c|c|c|c|c|c|c|c|c|c|c|c|c|c|c|c|}
\hline (19) & inmanas & Posolety & 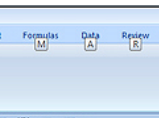 & (6) & ongtiper & & Wh tedellt & them-Merer & resent bred & & & & \multicolumn{3}{|c|}{ 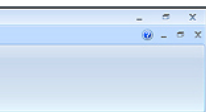 } \\
\hline \multicolumn{16}{|c|}{ (1) (2) } \\
\hline 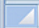 & A & B & c & D & $E$ & $\mathrm{~F}$ & G & H & 1 & $\mathrm{~J}$ & k & L & M & $\mathrm{N}$ & \\
\hline \multicolumn{16}{|l|}{1} \\
\hline \multirow{2}{*}{\multicolumn{16}{|c|}{$\begin{array}{l}2 \\
3\end{array}$}} \\
\hline & & & & & & & & & & & & & & & \\
\hline \multicolumn{8}{|l|}{4} & & & & & & & & \\
\hline \multicolumn{16}{|l|}{5} \\
\hline 6 & & & DateTime & Year & Month & MonthYr & Day & Hour & Date & Time & WeekdayNum & n Weekday & Daytype & Holiday & Days \\
\hline 7 & & & 5/1/08 12:00 AM & 2008 & 8 May & May 2008 & 1 & 0 & $5 / 1 / 2008$ & $12: 00 \mathrm{AN}$ & & 4 Thursday & Weekday & No & \\
\hline 8 & & & 5/1/08 1:00 AM & 2008 & 8 May & May 2008 & 1 & 1 & $5 / 1 / 2008$ & $31: 00 \mathrm{AN}$ & & 4 Thursday & Weekday & No & \\
\hline 9 & & & 5/1/08 2:00 AM & 2008 & 8 May & May 2008 & 1 & 2 & $5 / 1 / 2008$ & $2: 00 \mathrm{AN}$ & & 4 Thursday & Weekday & No & \\
\hline 10 & & & 5/1/08 3:00 AM & 2008 & 8 May & May 2008 & 1 & 3 & $5 / 1 / 2008$ & $3: 00 \mathrm{AN}$ & & 4 Thursday & Weekday & No & \\
\hline 11 & & & 5/1/08 4:00 AM & 2008 & 8 May & May 2008 & 1 & 4 & $5 / 1 / 2008$ & $34: 00 \mathrm{AN}$ & & 4 Thursday & Weekday & No & \\
\hline 12 & & & 5/1/08 5:00 AM & 2008 & 8 May & May 2008 & 1 & 5 & $5 / 1 / 2008$ & $5: 00 \mathrm{AN}$ & & 4 Thursday & Weekday & No & \\
\hline 13 & & & 5/1/08 6:00 AM & 2008 & 8 May & May 2008 & 1 & 6 & $5 / 1 / 2008$ & $36: 00 \mathrm{AN}$ & & 4 Thursday & Weekday & No & \\
\hline 14 & & & 5/1/08 7:00 AM & 2008 & 8 May & May 2008 & 1 & 7 & $5 / 1 / 2008$ & 3:00 AN & & 4 Thursday & Weekday & No & \\
\hline 15 & & & 5/1/08 8:00 AM & 2008 & 8 May & May 2008 & 1 & 8 & $5 / 1 / 2008$ & $8: 00 \mathrm{AN}$ & & 4 Thursday & Weekday & No & \\
\hline 16 & & & 5/1/08 9:00 AM & 2008 & 8 May & May 2008 & 1 & 9 & $5 / 1 / 2008$ & 3 9:00 AN & & 4 Thursday & Weekday & No & \\
\hline 17 & & & 5/1/08 10:00 AM & 2008 & 8 May & May 2008 & 1 & 10 & $5 / 1 / 2008$ & $10: 00 \mathrm{AN}$ & & 4 Thursday & Weekday & No & \\
\hline 18 & & & 5/1/08 11:00 AM & 2008 & 8 May & May 2008 & 1 & 11 & $5 / 1 / 2008$ & $311: 00 \mathrm{AN}$ & & 4 Thursday & Weekday & No & \\
\hline 19 & & & 5/1/08 12:00 PM & 2008 & 8 May & May 2008 & 1 & 12 & $5 / 1 / 2008$ & $12: 00 \mathrm{PN}$ & & 4 Thursday & Weekday & No & \\
\hline 20 & & & 5/1/08 1:00 PM & 2008 & 8 May & May 2008 & 1 & 13 & $5 / 1 / 2008$ & $31: 00 \mathrm{PN}$ & & 4 Thursday & Weekday & No & \\
\hline 21 & & & 5/1/08 2:00 PM & 2008 & 8 May & May 2008 & 1 & 14 & $5 / 1 / 2008$ & $32: 00 \mathrm{PN}$ & & 4 Thursday & Weekday & No & \\
\hline 22 & & & 5/1/08 3:00 PM & 2008 & 8 May & May 2008 & 1 & 15 & $5 / 1 / 2008$ & $3: 00 \mathrm{PM}$ & & 4 Thursday & Weekday & No & \\
\hline 23 & & & 5/1/08 4:00 PM & 2008 & 8 May & May 2008 & 1 & 16 & $5 / 1 / 2008$ & 4:00 PM & & 4 Thursday & Weekday & No & \\
\hline 24 & & & 5/1/08 5:00 PM & 2008 & 8 May & May 2008 & 1 & 17 & $5 / 1 / 2008$ & 5:00 PM & & 4 Thursday & Weekday & No & \\
\hline 25 & & & 5/1/08 6:00 PM & 2008 & 8 May & May 2008 & 1 & 18 & $5 / 1 / 2008$ & 6:00 PM & & 4 Thursday & Weekday & No & \\
\hline 26 & & & 5/1/08 7:00 PM & 2008 & 8 May & May 2008 & 1 & 19 & $5 / 1 / 2008$ & 7:00 PM & & 4 Thursday & Weekday & No & \\
\hline 27 & & & 5/1/08 8:00 PM & 2008 & 8 May & May 2008 & 1 & 20 & $5 / 1 / 2008$ & 8:00 PM & & 4 Thursday & Weekday & No & \\
\hline 28 & & & 5/1/08 9:00 PM & 2008 & 8 May & May 2008 & 1 & 21 & $5 / 1 / 2008$ & 9:00 PM & & 4 Thursday & Weekday & No & \\
\hline 29 & & & 5/1/08 10:00 PM & 2008 & 8 May & May 2008 & 1 & 22 & $5 / 1 / 2008$ & $10: 00 \mathrm{PM}$ & & 4 Thursday & Weekday & No & \\
\hline \multicolumn{16}{|c|}{ naten } \\
\hline
\end{tabular}

Figure 10: Processed "raw data” in ECAM

ECAM will automatically generate certain columns, depending on the information input by the user. In this example, the columns generated are the Date/Time, Year, Month, MonthYr, Day, Hour, Date, Time, WeekdayNum, Weekday, Daytype, Holiday, Dayschedule, Occupance, 1degBin, 5degBin, TempRng, DateRng, OAT, and WholeBuildingElectrickWh. Some columns will be blank depending on input selection by the user. For example, if OAT data was not included, then the 1degBin, $5 \mathrm{degBin}$, and TempRng columns would be blank and the OAT column would not exist. ECAM will use all of the generated information to produce the plots discussed in the upcoming sections. 


\subsection{Definition of Points}

The second item under the ECAM dropdown menu is the "definition of points" option. This option allows the user to provide specific information to ECAM by mapping points, and then ECAM has the ability to generate charts and metrics from the provided information, and perform some normalizations. This step is necessary to generate charts, and if skipped, ECAM will produce no results. After selecting the definition of points sub-menu, a window will pop-up (Figure 11) asking for some basic building information. Here the user can input the building area to allow for normalization of the data and metrics by square foot. There is also a voltage input ${ }^{2}$ for three-phase equipment. If one or both pieces of information are unknown, ECAM has default values of 100,000 sf and 480 volts already input.

After selecing OK, a new window to define data by system, equipment, and measurement comes up (Figure 12) with a points list, mapped points, subsystems, subsystem components, and component measurements window.

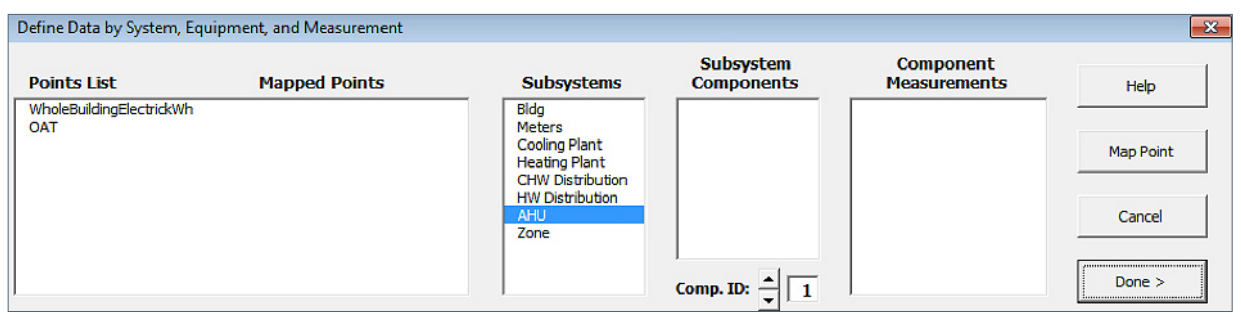

Figure 12: Define or "Map" the Points

For interval data analysis, there should only be two points listed: the whole building load and the outdoor air temperature. The subsystems list consists of building (Bldg), meters, cooling plant, heating plant, chilled water distribution (CHW Distribution), hot water distribution (HW Distribution), air handling unit (AHU), and zone. For interval data analysis, only the Bldg and meters subsystems are required. Clicking on any subsystem will bring up a new list of subsystem components, and clicking on a subsystem component gives another list in the component measurements. Sometimes ECAM must be refreshed when first defining points, so the user must un-select and then re-select a subsystem to get the components to load.

To start mapping the points, select either point under the points list. If the point is outdoor air temperature, click it and then click the Bldg subsystem. The only subsystem component that loads will be "Ambient." Select it and then Bldg_TempOa will appear under the component measurements. Select Bldg_TempOa and then click "Map Point" on the right hand side. If done correctly, you will see Figure 13 below.

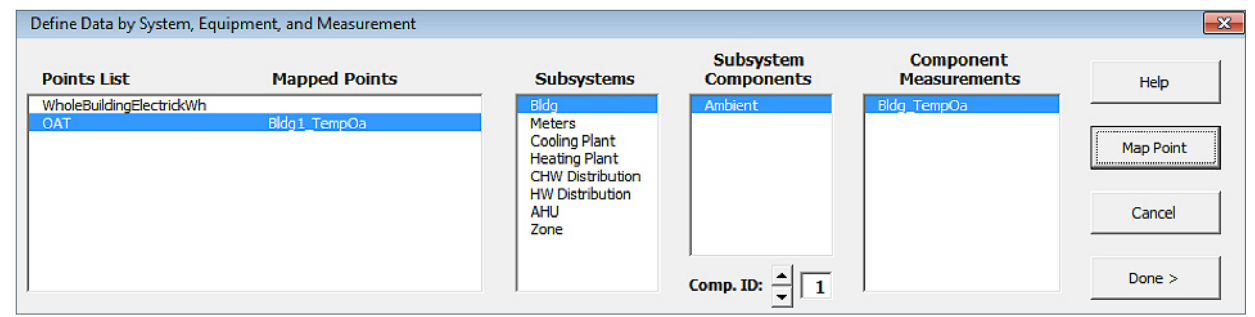

Figure 13: Example of OAT being Mapped in ECAM

\section{Building Information \\ What is the building area? \\ 100,0001 sq. feet}

What is the Voltage for 3-phase equipment?

480 volts

OK

Figure 11: Building Information after Selecting "Definition of Points"

\footnotetext{
${ }^{2}$ The voltage input is not relevant for this analysis and can be ignored.
} 
You can see that ECAM highlights your selection in blue, and after selecting the "Mapped Point" button, Bldg1_TempOa appears under the "Mapped Points" next to the Points List. Now select the whole building consumption under the points list. Under subsystems, select meters. The subsystem components list will have Meter_Elec and Meter_NaGas, select Meter_Elec. Now, under the component measurements list, will be ElecMtr_kW and ElecMtr_kWh. Select the appropriate measurement, depending on how the whole building consumption data was measured. In this case, ElecMtr_kWh is selected, and now under the mapped points list you will see ElecMtr1_kWh (Figure 14).

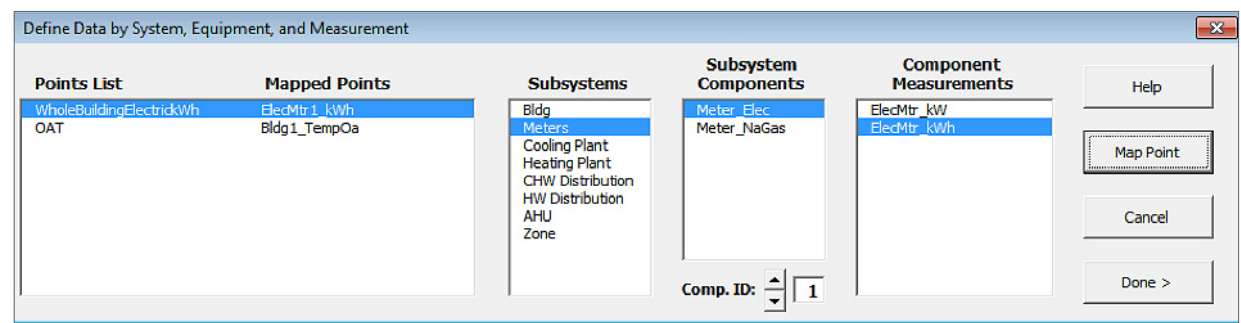

Figure 14: Example of Whole Building Consumption being Mapped in ECAM

The only thing that has not been addressed in this section is the Comp. ID (component ID) at the bottom of the "Define Data by System, Equipment, and Measurement" window. ECAM defaults this to 1, and you will see that both of the mapped points have a 1 in their mapped point name. This function gives the ability to map different buildings or systems with different component IDs. If you had two buildings, you would change the Comp. ID to 2, and map the points for the new building. The only thing that will change in the "Mapped Points" section is there will be a 2 instead of a 1 in the point name.

After the points are defined, some normalized and calculated points will be created and added to the points list automatically. All $\mathrm{kWh}$ points will automatically have a normalized point added as watt-hours per square foot (Wh_perSF). Here are some examples (Table 1):

Table 1: List of Points Added in ECAM after Mapping the Whole Building Energy Consumption

\begin{tabular}{|l|l|}
\hline Point Type & Normalized or calculated point \\
\hline$k W h$ & Watts per square foot (Wh_perSF) \\
\hline$k W h$ & $\begin{array}{l}\text { Equipment status (only if a status point is not available) } \\
>3 \% \text { of } \max =\text { "On" } \\
<=3 \% \text { of } \max =\text { "Off" }\end{array}$ \\
\hline
\end{tabular}




\subsection{Create Schedules}

The next item under the ECAM dropdown menu is an option to create schedules. Clicking on this option brings up a table that has options to input occupancy times for each day of the week, and typical building or equipment startup/shutdown times. The default table looks like Figure 15.

This table has three tabs. The first tab is for day schedules. You can customize up to 10 different schedules in this window and enter typical startup/shutdown times for each schedule. To have a 24-hour occupied schedule, select 12:00 AM as the start time and 11:59 $\mathrm{PM}$ as the end time. To have a 24-hour unoccupied schedule, select 12:00 AM as the start time and 12:00 AM as the end time. Once all known schedules are entered, select the "Week Schedules" button at the bottom of the table. This table will initially be blank, but gives you the option to select a day schedule from tab 1 for a specific day of the week. You can name the schedule at the top of the table, and create up to five different schedules. A typical input schedule for an office building might look like Figure 16, with Monday through Friday having the same schedule, Saturday and Sunday having a different schedule, and holidays having their own schedule. Under schedule name for an office building, one might select "All Year" as the schedule name; occupancy would be the same year round for this type of building.

Once this table is filled out, select the "Annual Schedule" button at the bottom. The last tab will allow you to apply your schedules to specific date ranges (Figure 17). The starting date is defaulted to January 1st, but other schedules are blank for later times in the year. If a schedule isn't input, ECAM will default daytype to be occupied.

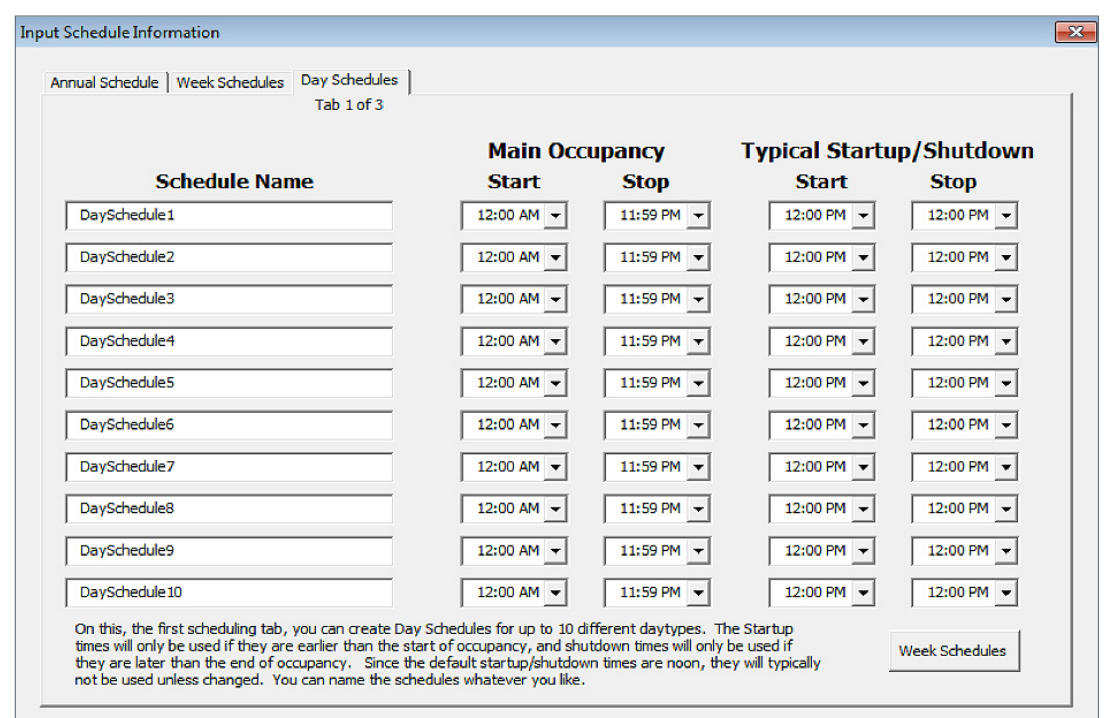

Figure 15: Creating Schedules in ECAM

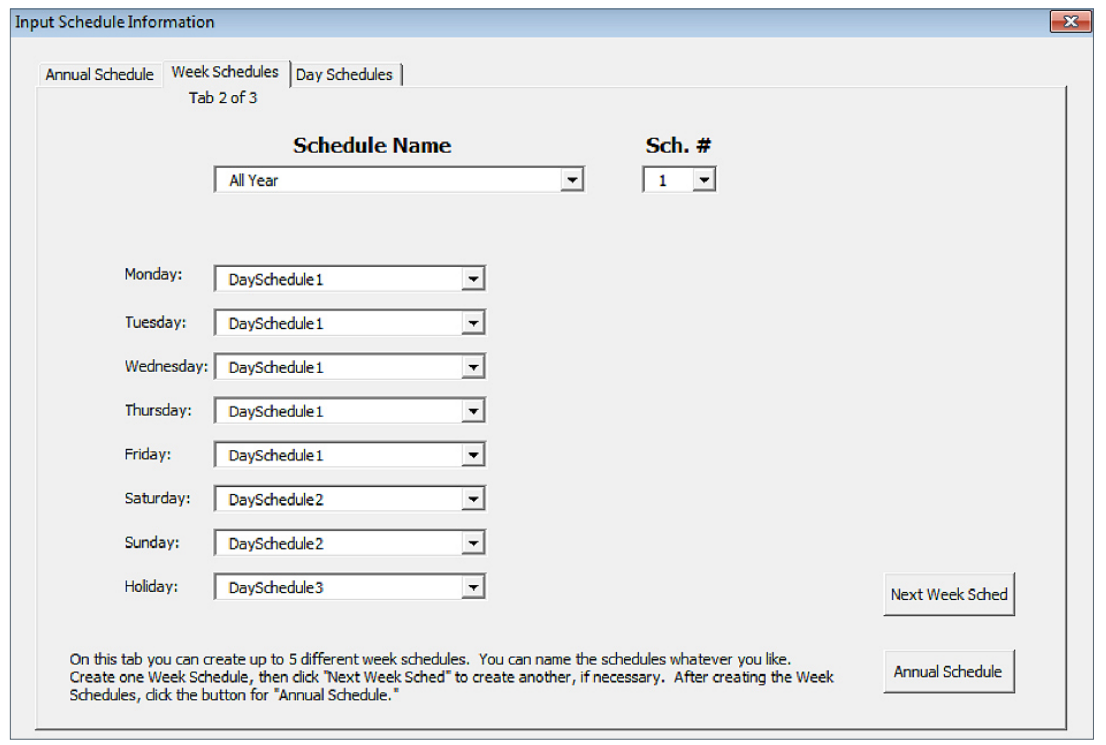

Figure 16: Second Tab for Adding Schedules (Week Schedules)

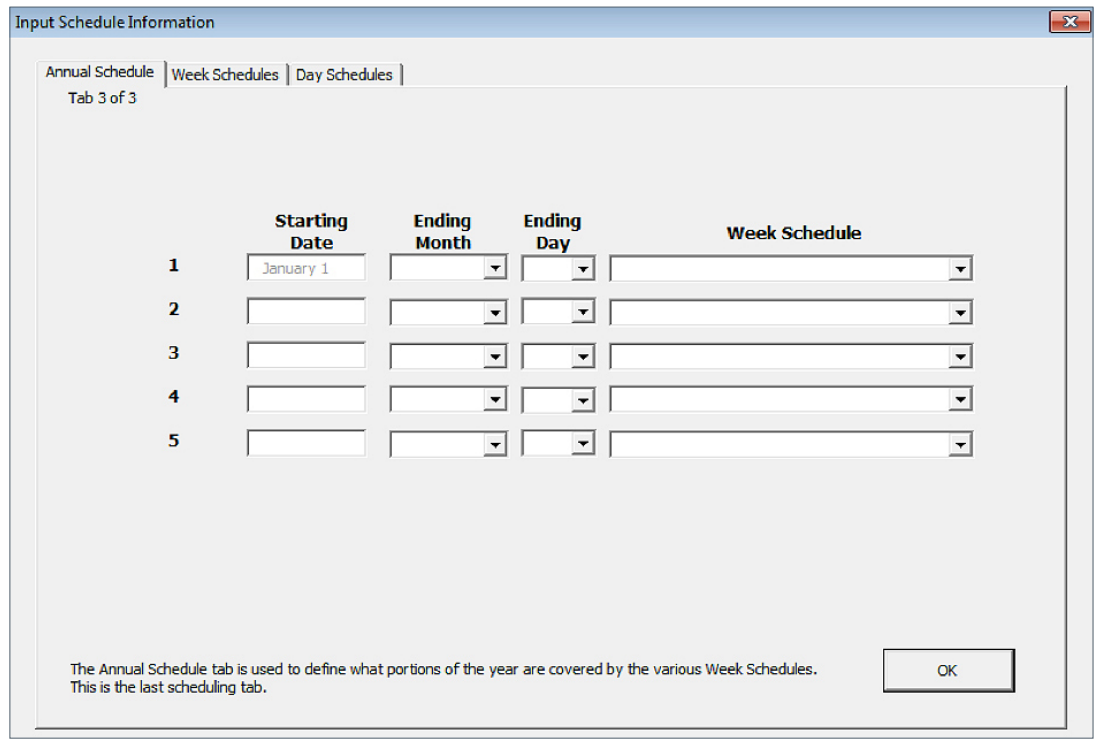

Figure 17: Annual Schedules Input Tab 


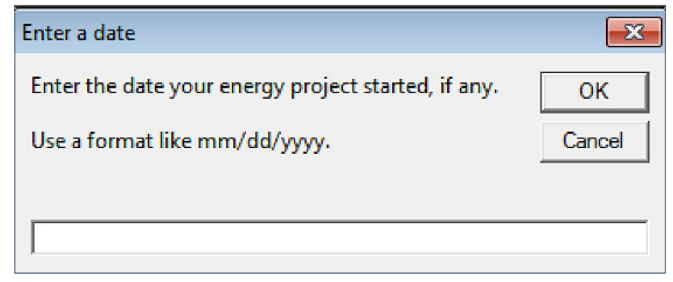

Figure 18: Entering a Date When an Energy Project Started for Comparison of Pre/Post

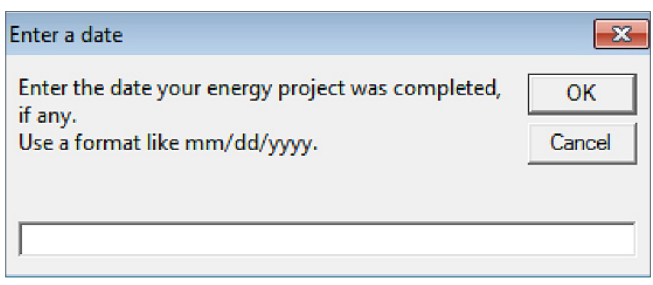

Figure 19: Entering a Date When an Energy Project Finished for Comparison of Pre/Post

\subsection{Input Dates for Comparison of Pre and Post Consumption Data}

This menu item will prompt (as shown in Figure 18 and Figure 19) you for the input of two dates: the date when an energy project was started, and the date when it was completed. An additional data field will be created that can be used for categorization and filtering of the data in later charts.

\subsection{ECAM Utilities}

This section describes additional ECAM Utilities (Figure 20).

\begin{tabular}{|c|c|c|c|c|c|c|c|c|c|c|c|c|c|}
\hline & 5.9 & & & & & & & & & & & & SU Hotel_EC \\
\hline (2) & 40 & Home & Insert & Page Layout & ormulas & & Data & Review & View & & Developer & Add-Ins & \\
\hline & $E$ & CAM - & & & & & & & & & & & \\
\hline & $\ldots+$ & Select Data & & & & & & & & & & & \\
\hline & $:$ & Definition o & f Points & & & & & & & & & & \\
\hline & (1) & Create $\underline{\underline{s}}$ che & dules & & & & & & & & & & \\
\hline & 31 & Input Dates & for Com & ison of Pre and Post & & 亩 & $=$ & & & & & & \\
\hline & 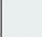 & Iime Series & Charts & & 卜 & & & & & & & & \\
\hline & 哺昼 & Load Profile & as Box $P$ & $s$ (Excel 2007/10) & & & $E$ & $\mathrm{~F}$ & G & $\mathrm{H}$ & 1 & J & $\mathrm{K}$ \\
\hline & & Scatter Char & & & > & & & & & & & & \\
\hline & Wll & Load Durati & on Chart & int Frequency Distribu & ution) & & & & & & & & \\
\hline & 国 & Chart to Che & ck Inpu & hedule (Excel 2007/10) & & & & & & & & & \\
\hline & & Matrix Chart & & & > & & & & & & & & \\
\hline & $M$ & Metrics for $P$ & oints $\mathrm{NC}$ & alized per Sq. Foot & & bnt & th & MonthYr & Day & Hour & Date & Time & Weekday \\
\hline & & Create $\underline{\text { Othe }}$ & Metrics & & > & $y$ & & May 2008 & 1 & 0 & $5 / 1 / 2008$ & $12: 00 \mathrm{AM}$ & \\
\hline & & Data Summa & ries & & > & $y$ & & May 2008 & 1 & 1 & $5 / 1 / 2008$ & 1:00 AM & \\
\hline & & PNNL Re-Tur & ing & & , & ay & & May 2008 & 1 & 2 & $5 / 1 / 2008$ & 2:00 AM & \\
\hline & $=$ & ECAM Utiliti & & & $\rightarrow$ & & 7 & A. anan & matio & FCAM & -1. Laman & $\sim \mathrm{Mm}$ & \\
\hline & 9 & & & & & 证 & 学 & ivert tave rom & & Clution & List & $\mathrm{M}$ & \\
\hline & \% & ECAM Help & & & & \# & & ate $\underline{B}$ in Data fro & rom Ter & emperat & tures & $\mathrm{M}$ & \\
\hline & 囯 & About ECAM & & & & 国 & ${ }_{+}^{2}+\mathrm{Nes}$ & v Data was add & ded to & o "Data" & " worksheet & M & \\
\hline & 14 & & & 5/1/08 7:00 AM & $2008 \mathrm{~N}$ & M缉 & & oy Worksheet a & and Up & pdate E & ECAM Chart Sou & $\mathrm{M}$ & \\
\hline & 15 & & & 5/1/08 8:00 AM & $2008 \mathrm{~N}$ & May & & May 2008 & 1 & 8 & $5 / 1 / 2008$ & $8: 00 \mathrm{AM}$ & \\
\hline & 16 & & & 5/1/089:00 AM & $2008 \mathrm{~N}$ & May & & May 2008 & 1 & 9 & $5 / 1 / 2008$ & 9:00 AM & \\
\hline & 17 & & & $5 / 1 / 0810: 00 \mathrm{AM}$ & $2008 \mathrm{~N}$ & May & & May 2008 & 1 & 10 & $5 / 1 / 2008$ & 10:00 AM & \\
\hline & 18 & & & $5 / 1 / \cap 811 \cdot n \cap A \mathrm{MA}$ & $20 n$ a & & & May anne & 1 & 11 & $5 / 1 / 2 n n e$ & $11 \cdot \cap \cap \wedge \mathrm{M}$ & \\
\hline
\end{tabular}

Figure 20: ECAM Utilities

\subsubsection{Convert Table format to ECAM List Format}

This utility converts utility company data into an acceptable ECAM formatted data, and is discussed in detail earlier in Chapter 3.1.

\subsubsection{New Data was added to "Data" Worksheet}

If additional trend data is gathered, i.e., more time stamps or more points, it can be pasted into the "Data" worksheet in the appropriate place. This utility makes sure that the additional data is available to all the features and previously created menus and charts. Once new data is added, simply select this option, and the worksheet will be updated to include the new data.

\subsubsection{Copy Worksheet and Update ECAM Chart Source}

Sometimes it is useful to select multiple months in ECAM charts, which is possible with the Pivot Tables, but only 1 month can be selected and displayed at a time. This utility makes it possible to copy the worksheet and chart, but select a new month or day of interest. A specific example of using this utility will be discussed later in the report. 


\section{Features: Creating Time Series Charts}

This section describes how time series charts can be created using ECAM charting features. The first step in the process of creating the charts is to select the "Time Series Charts" submenu from the ECAM menu, as shown in Figure 21. The list of options in this submenu will be discussed below.

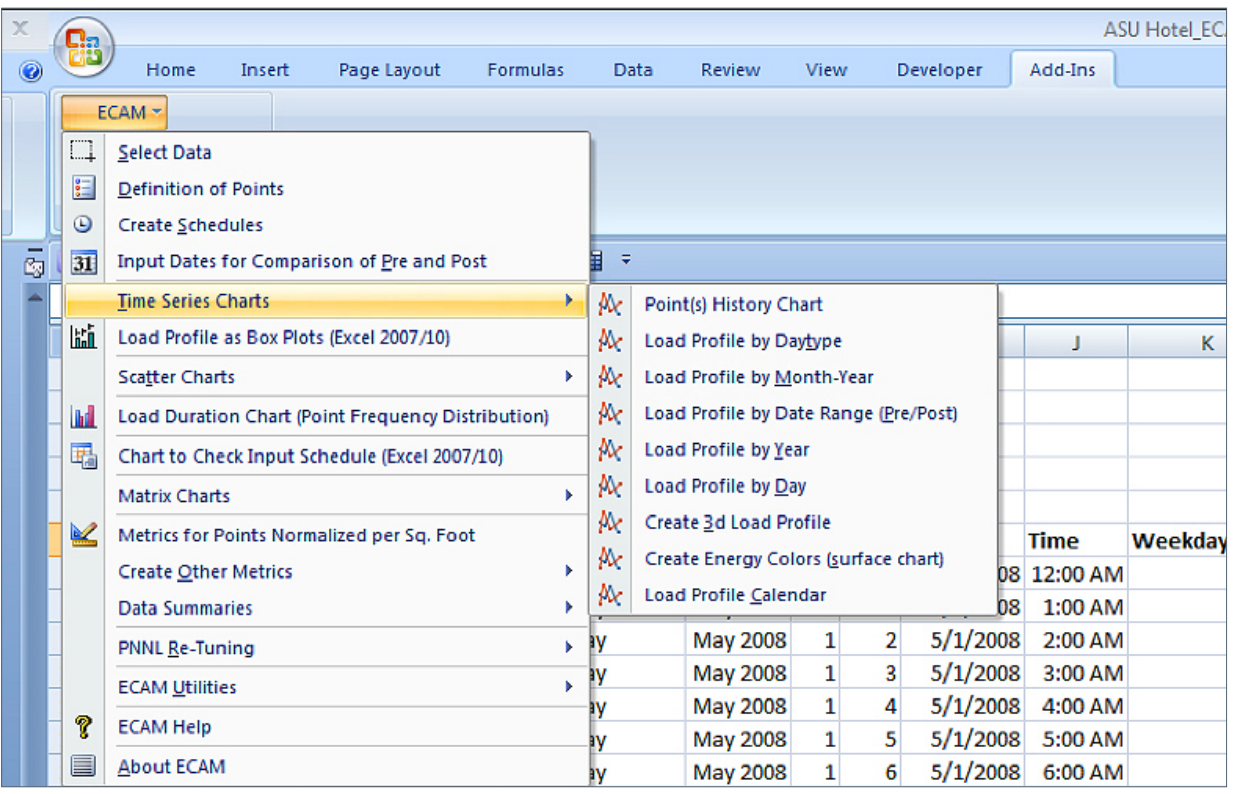

Figure 21: Time Series Charts

\subsection{Point(s) History Chart}

The first time series chart is the Point(s) History Chart. Click this chart, and a window shown in Figure 22 will pop up asking you to select the name(s) of the point(s) you want to include in the metrics or chart. For interval data analysis, there will only be one point of interest, the whole building electricity consumption.

You have to select the name of the point, so just the cell where the point name header exists (i.e., Figure 23). Once selected, click OK and ECAM will generate the plot in another sheet. Figure 23 below should be similar to what you see with the selection coming from column $\mathrm{U}$, on the heading titled "ElecMtr1." The resulting plot is shown in Figure 24. This plot will have the raw data plotted for the entire dataset. The y-axis title will say something like Avg ElecMtr1_kWh. ECAM defaults this title as an average, but really it is the raw data just plotted. For all other time series plots, the data will be plotted as an average. You can manually change this y-axis label using standard Excel graphing tools.

\begin{tabular}{|c|c|c|c|c|c|c|c|c|c|c|c|c|c|}
\hline $\mathrm{J}$ & $\mathrm{k}$ & L & M & $\mathrm{N}$ & 0 & $\mathrm{P}$ & Q & $\mathrm{R}$ & s & $T$ & $u$ & $\mathrm{v}$ & \\
\hline & & & & & & & & & & & & & \\
\hline & & & & & & & & & & & & & \\
\hline & & & & & & & & & & & & & \\
\hline & & & & & & & & & & & \multicolumn{2}{|c|}{ WholeBui OAT } & \\
\hline Time & WeekdayNum & n Weekday & Daytype & Holiday & DaySchedule & Occupancy & 1degBin & 5degBin & TempRng & DateRng & (ElecMtr1 & Bldg1_Ter & Day \\
\hline 12:00 AM & & 4 Thursday & Weekday & No & DaySchedule1 & Occ & 52 & 52.5 & under 55 & Before 1- & 521.64 & 51.8 & 0.0 \\
\hline 1:00 AM & & 4 Thursday & Weekday & No & DaySchedule1 & Occ & 50 & 52.5 & under 55 & Before 1- & 527.16 & 50 & 0.0 \\
\hline 2:00 AM & & 4 Thursday & Weekday & No & DaySchedule1 & Occ & 48 & 47.5 & under 55 & Before 1- & 532.68 & 48.2 & 0.0 \\
\hline 3:00 AM & & \multirow{2}{*}{\multicolumn{2}{|c|}{ Point Selection }} & & & pcc & 48 & 47.5 & under 55 & Before 1- & 532.68 & 48.2 & 0.0 \\
\hline 4:00 AM & & $4 \mathrm{TH}$ Point sel & & & & pcc & 48 & 47.5 & under 55 & Before 1- & 527.16 & 48.2 & 0.0 \\
\hline 5:00 AM & & \multirow{2}{*}{\multicolumn{3}{|c|}{$\begin{array}{l}\text { Select the name(s) of the } \\
\text { in the Metics or Chart. }\end{array}$}} & ou want to include & pcc & 48 & 47.5 & under 55 & Before 1- & 549.24 & 48.2 & 0.0 \\
\hline 6:00 AM & & & & & & pcc & 50 & 52.5 & under 55 & Before 1- & 596.16 & 50 & 0.0 \\
\hline 7:00 AM & & \multicolumn{2}{|c|}{ Data! \$\$\$ $6 \mid$} & - & $\mathrm{OK}$ & bcc & 52 & 52.5 & under 55 & Before 1- & 676.2 & 51.8 & 0.0 \\
\hline $8: 00 \mathrm{AM}$ & & $4 \mathrm{TH}$ & & & & bcc & 54 & 52.5 & under 55 & Before 1- & 659.64 & 53.6 & 0.0 \\
\hline 9:00 AM & & 4 Thursday & Weekday & No & DaySchedule1 & Occ & 57 & 57.5 & 55 to 70 & Before 1- & 643.08 & 57.2 & 0.0 \\
\hline
\end{tabular}

Figure 23: Example of Choosing the Header or Point Name for the Point(s) History Chart

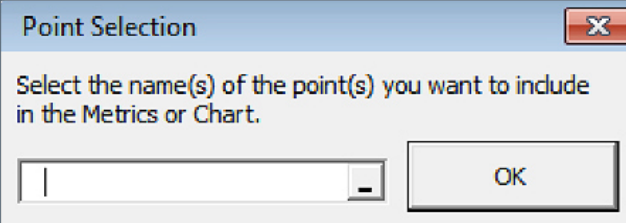

Figure 22: Point Selection for the Point(s) History Chart 


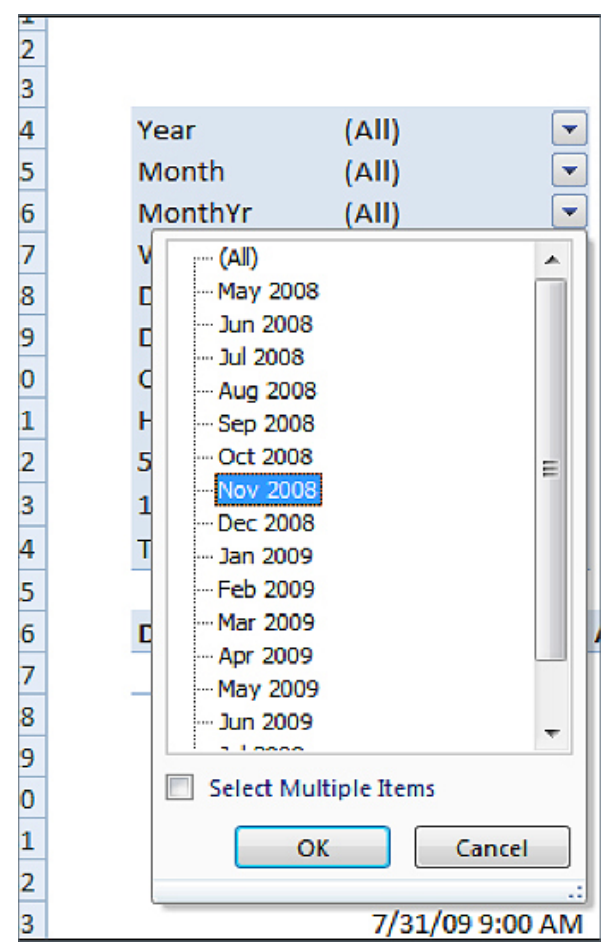

Figure 25: Using the Pivot Table to Modify Data Selection on the Point History Chart

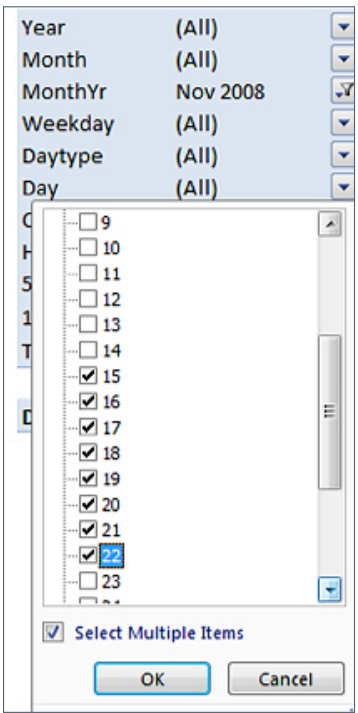

Figure 27: Using the Pivot Table to Select Specific Days to be Displayed on the Point History Chart

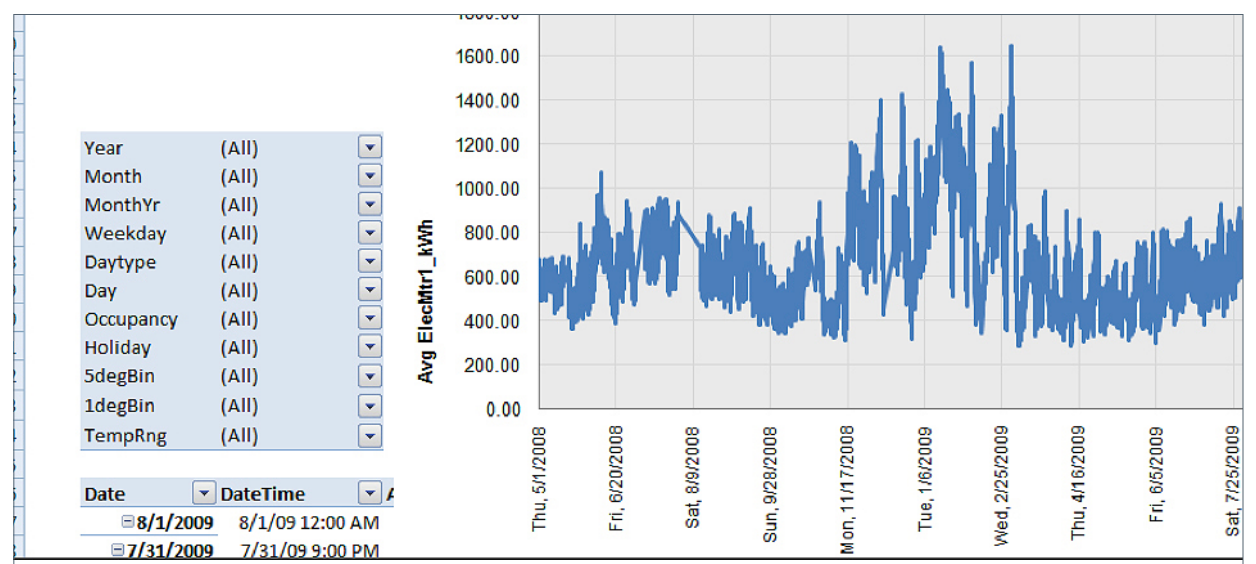

Figure 24: Point(s) History Chart Created in ECAM After Making Appropriate Data Selection

The built-in pivot tables in ECAM give the user the ability to select a specific month or day(s) within the data set, and the graph will update to reflect this (Figure 25). You can see that the time on the $\mathrm{x}$-axis from the figure above starts in May, 2008 and ends in July, 2009. Figure 26 shows data for only November 2008. To do this, you must click on the MonthYr column of the Pivot Table and select Nov2008 and hit OK (Figure 25). To select multiple months displayed on one graph, click on the "Select Multiple Items" checkbox, and click only the months you want to be displayed.

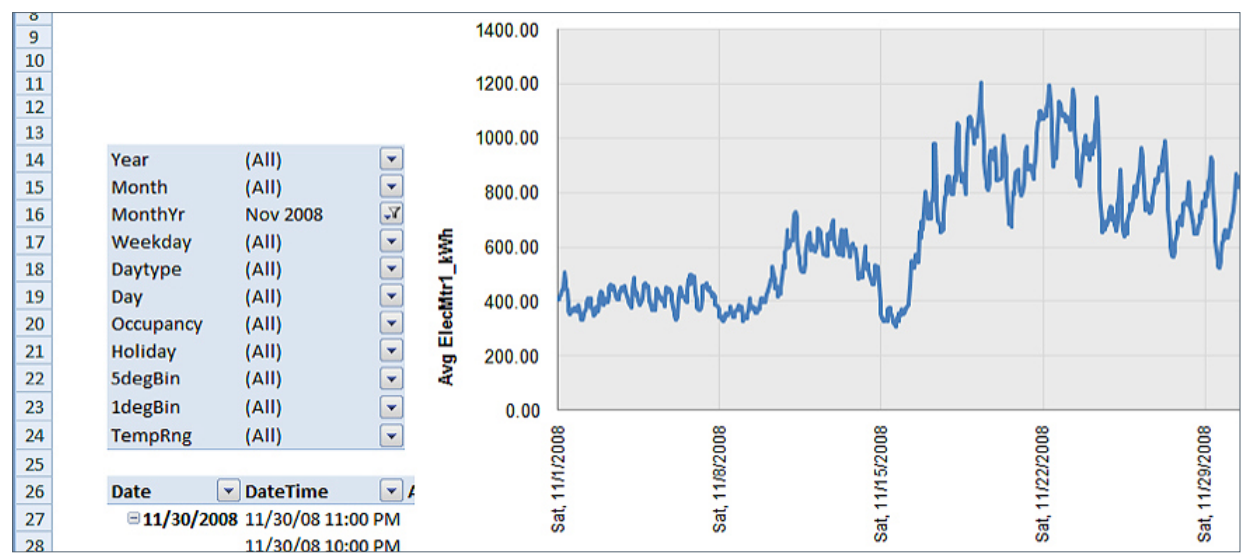

Figure 26: Point History Chart Filtered to Only Show November 2008.

You can see that the Pivot Table is now updated to show "Nov 2008" as the MonthYr chosen, and the graph represents that in Figure 26. To further narrow down to 1 week in November, 2008, simply select the "Day" and click on the "Select Multiple Items" checkbox, and then uncheck the "All" checkbox at the top. Then select the days of interest. For this example, the week of November 16th was chosen (Figure 27). Now, the table will show "Multiple Items" next to the "Day" category in Figure 28. 


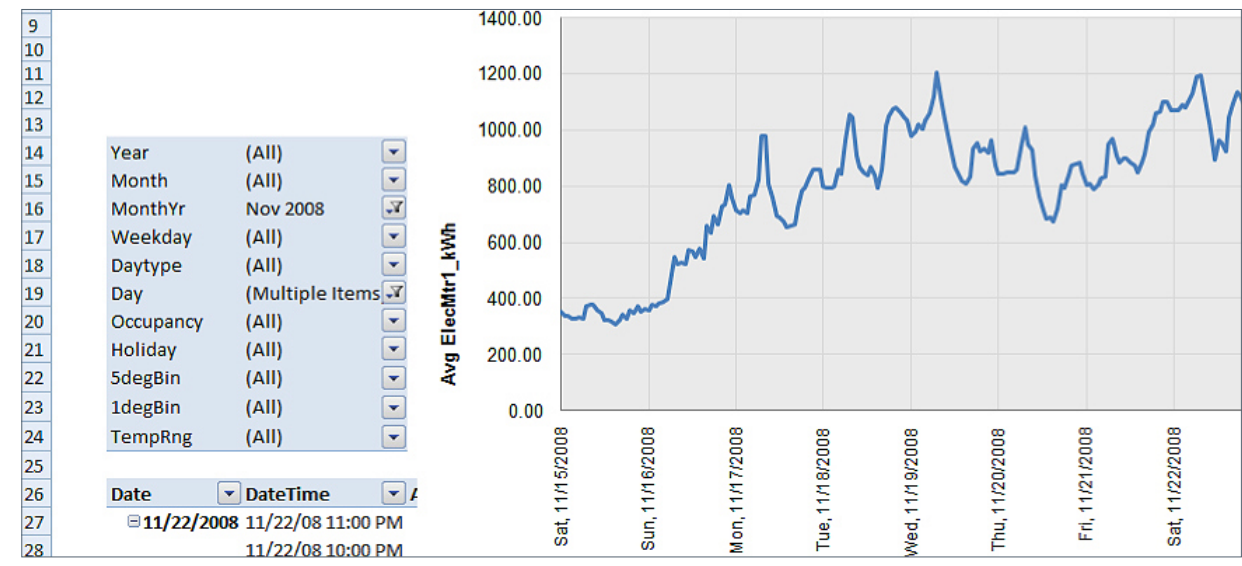

Figure 28: Using the Pivot Table to Only Select 1 Week of Data on the Point History Chart

Another good use of the Point History Charts is to compare different weeks or months side-by-side. You can accomplish this in ECAM using the matrix charts option. This option is for more advanced users, and is discussed in detail in Chapter 8.

\subsection{Load Profile by Daytype}

The second time series plot is the "Load Profile by Daytype." When you select this, a window will pop up again asking you to select the name(s) of the point(s) you want to include in the metrics or chart. There will be only one point, just like with the Point History Chart. Select the same point as you did for the Point History Chart, the whole building electricity consumption. ECAM will return the plot in a new sheet. The chart will have four series: One for the average weekday, Saturday, Sunday, and holiday during the date ranges. You can again use the Pivot Table to customize what you want to see in the chart, and use the matrix charts option discussed in Chapter 8 if you want to create multiple profiles by daytype and compare them side-by-side. This chart will be highlighted further in Chapter 7 while discussing the analysis, but can be seen below in Figure 29.

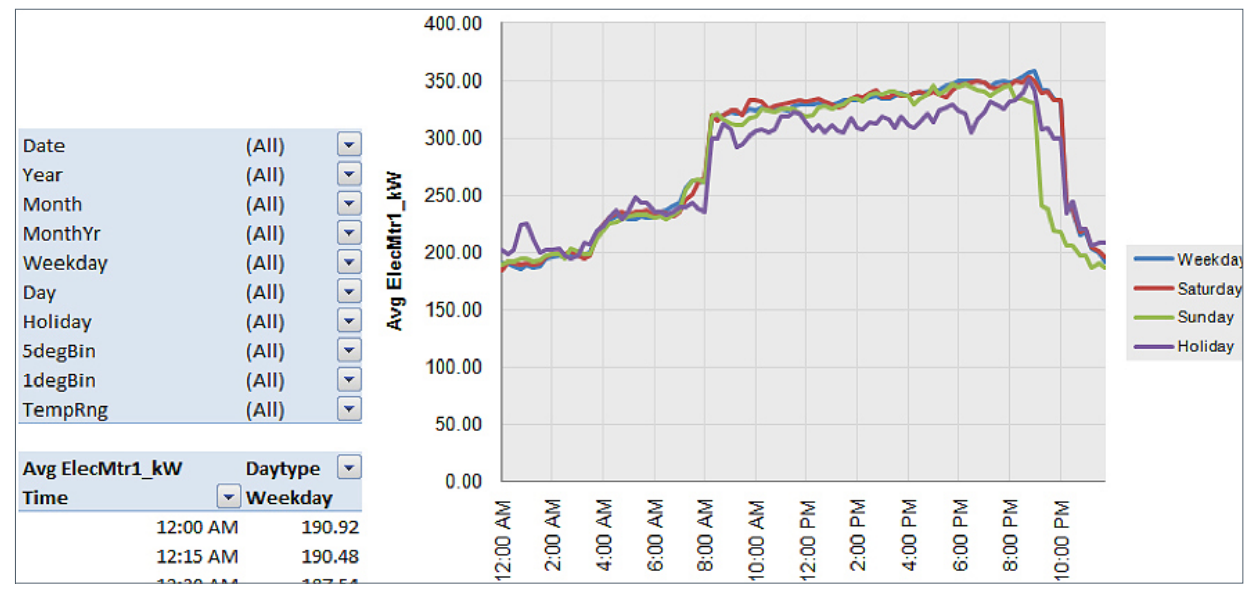

Figure 29: Load Profile by DayType 


\subsection{Load Profile by Month-Year}

The "Load Profile by Month-Year" returns a chart with the average consumption for each day in each month at each hour, and plots them all (average load profile for each month). Creating this chart is the same as the prior charts; one just needs to select the whole building electricity consumption and select OK. An example of such a plot is shown in Figure 30.

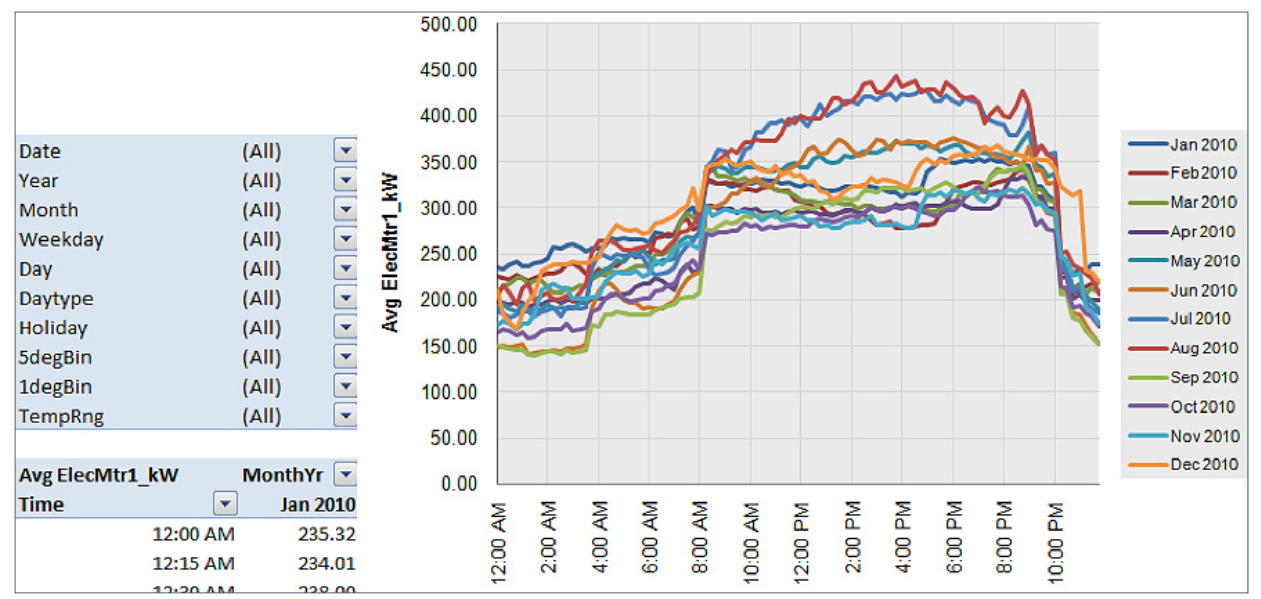

Figure 30: Load Profile by Month-Year

\subsection{Load Profile by Date Range (Pre/Post Retrofit)}

This chart is most useful if the user input dates for comparison of pre- and postretrofit, the 4th item in the ECAM dropdown menu, discussed above in Chapter 3.5. If this was done, the chart created will display three lines: before the changes, during the changes, and after the changes. See Chapter 6.2 for an example of how this can be applied and analyzed.

\subsection{Load Profile by Year}

This item plots an average load profile for the entire year in the data set, as shown in Figure 31. It is most useful if you have multiple years of data and you want to compare 1 year to the next. This chart is created the same way as the previous charts, again only requiring the selection of the whole building electricity consumption and selecting $\mathrm{OK}$.

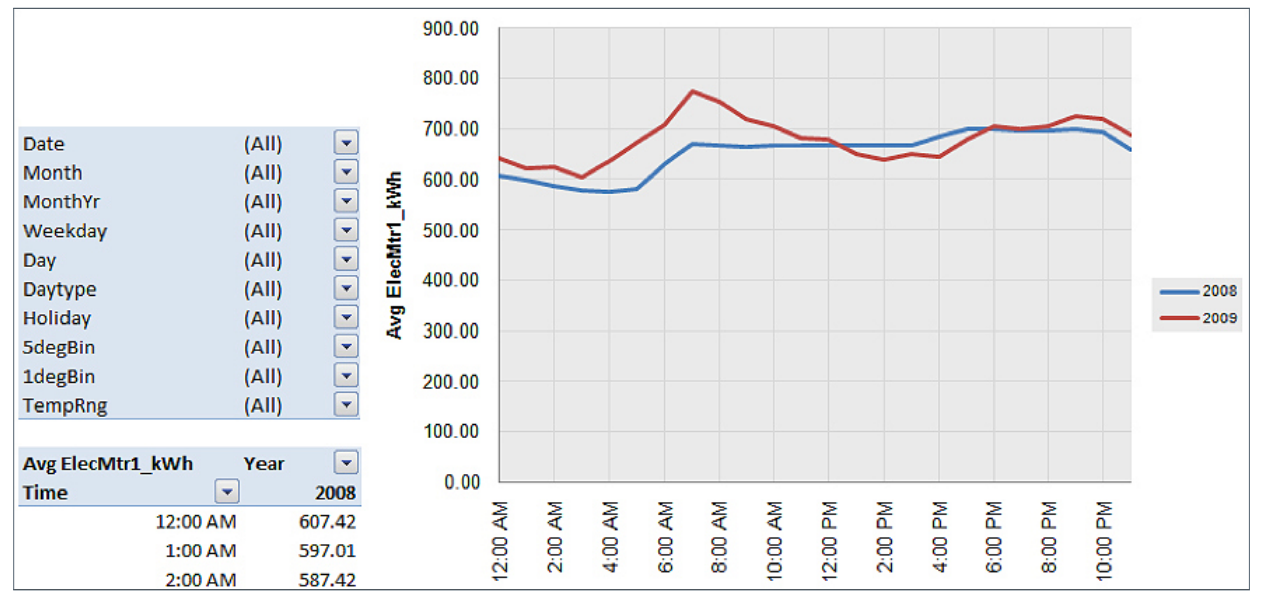

Figure 31: Load Profile by Year 


\subsection{Load Profile by Day}

The "Load Profile by Day" chart is a very important ECAM feature. This plot is needed to get the last three time series charts; $3 \mathrm{~d}$ load profile chart, energy colors chart, and load profile calendar. Creating the chart is the same as the charts above. Once you have created it, some changes are needed to get the remaining three charts.

Figure 32 gives the average consumption at each hour for each day during the year, i.e., every first day of the month, second day of the month, etc. To create the remaining three charts, you must change the MonthYr Pivot Table selection to a specific month. This was described above by clicking the dropdown tab and then clicking a specific month and hitting OK. You can see in Figure 33 that Jan 2009 was selected, and now shows in the MonthYr category. To get around the bug in ECAM, you must click the month directly, and not click on the "Select Multiple Items" option.

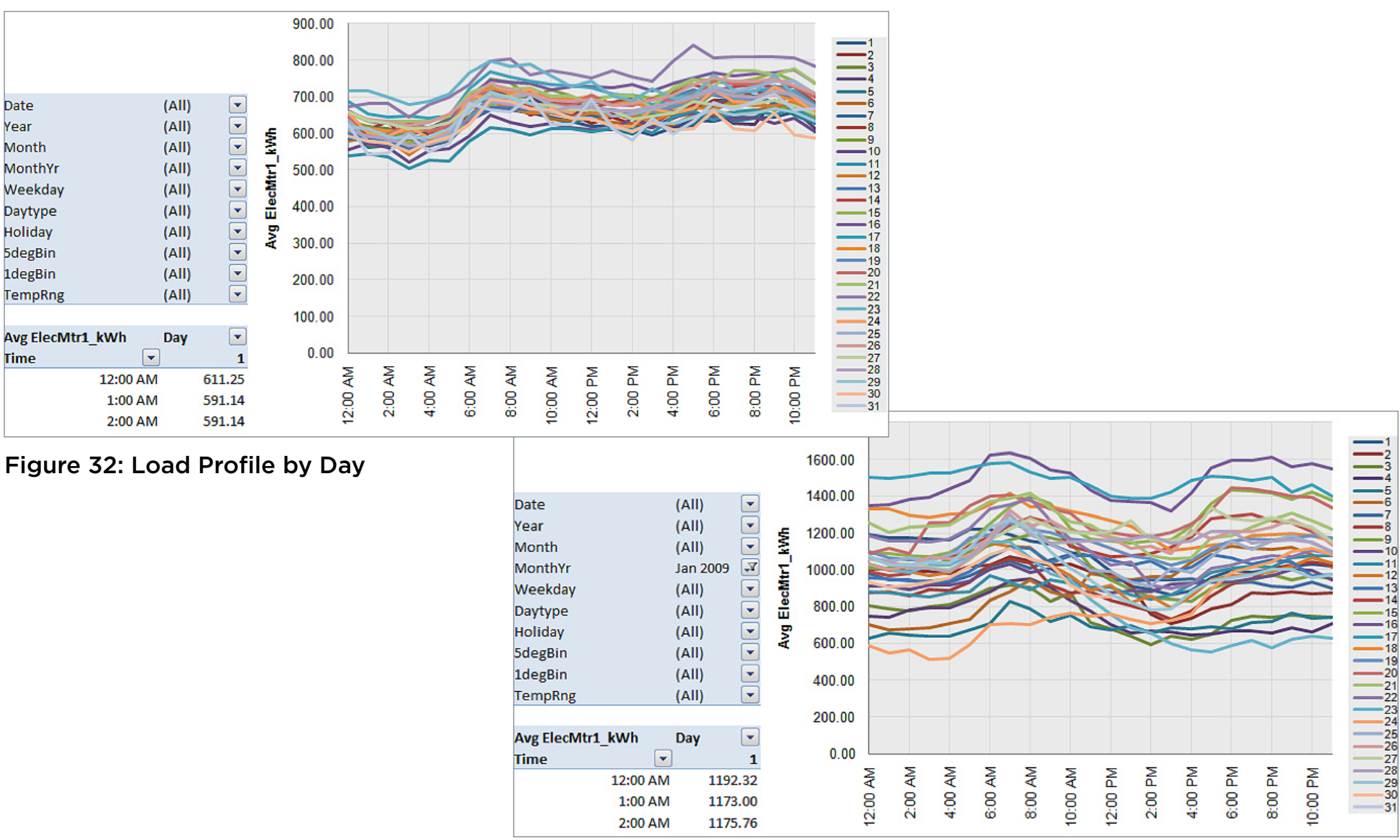

Figure 33: Load Profile by Day Filtered to January 2009 


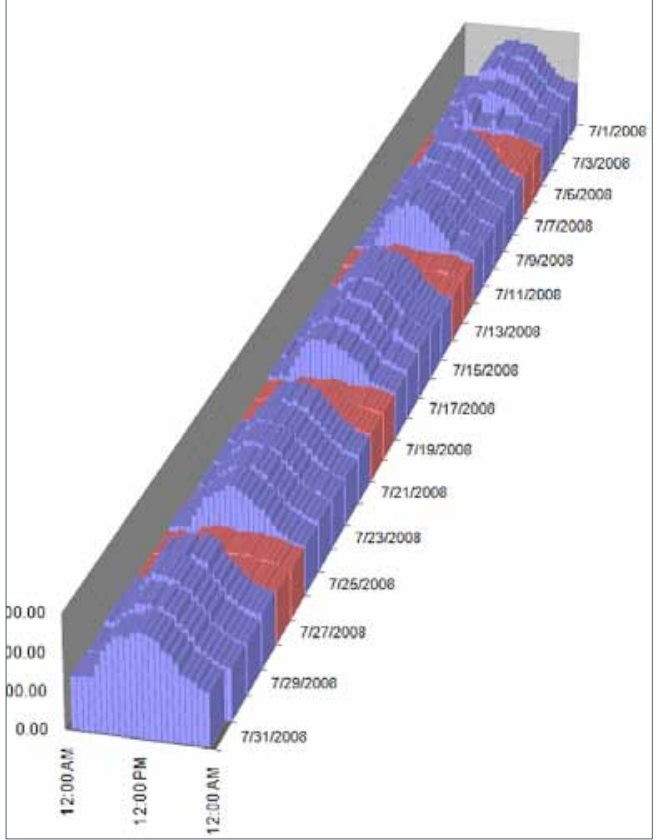

Figure 34: 3d Load Profile Created from the Load Profile by Day Chart

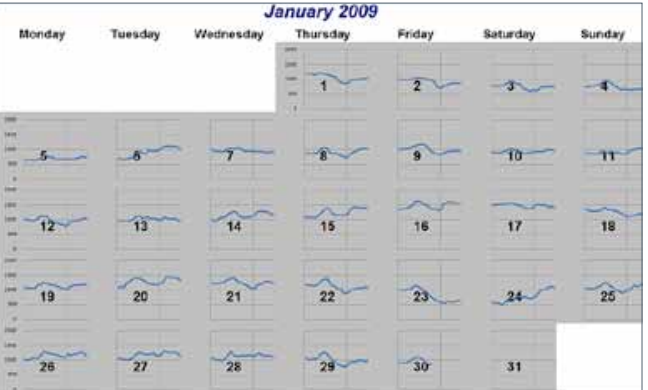

Figure 36: Load Profile Calendar for January 2009

\subsection{Create 3d Load Profile}

Now that the "Load Profile by Day" has been created, and the MonthYr has been changed to a specific month, the $3 \mathrm{~d}$ load profile can be created. This chart must be created while you are in the Load Profile by Day sheet with the MonthYr changed. You can see from Figure 34 that the corresponding $3 \mathrm{~d}$ plot is for July 2008, and that the weekends are shown in red while the weekdays are shown in blue. You will also notice that your original "Load Profile by Day" chart has been replaced with the $3 \mathrm{~d}$ plot. It is useful to utilize the ECAM utilities and make a copy of the "Load Profile by Day" before creating this chart to save the original in your workbook, because creating of the $3 \mathrm{~d}$ chart will replace the Load Profile by Day chart. You can now use the MonthYr dropdown menu to change from month to month within the $3 \mathrm{~d}$ plot.

\subsection{Create Energy Colors (surface chart)}

Starting again with the "Load Profile by Day" chart with Jan 2009 as the MonthYr from Figure 33, you can now create an energy colors or surface chart, as shown in Figure 35. This chart must be created from the Load Profile by Day chart. Select the "Create Energy Colors (surface chart)" from the ECAM dropdown menu. Once again, the "Load Profile by Day" chart is replaced by the surface chart, so making a copy before creating this chart is recommended. You can use the dropdown menu on MonthYr to highlight different months.

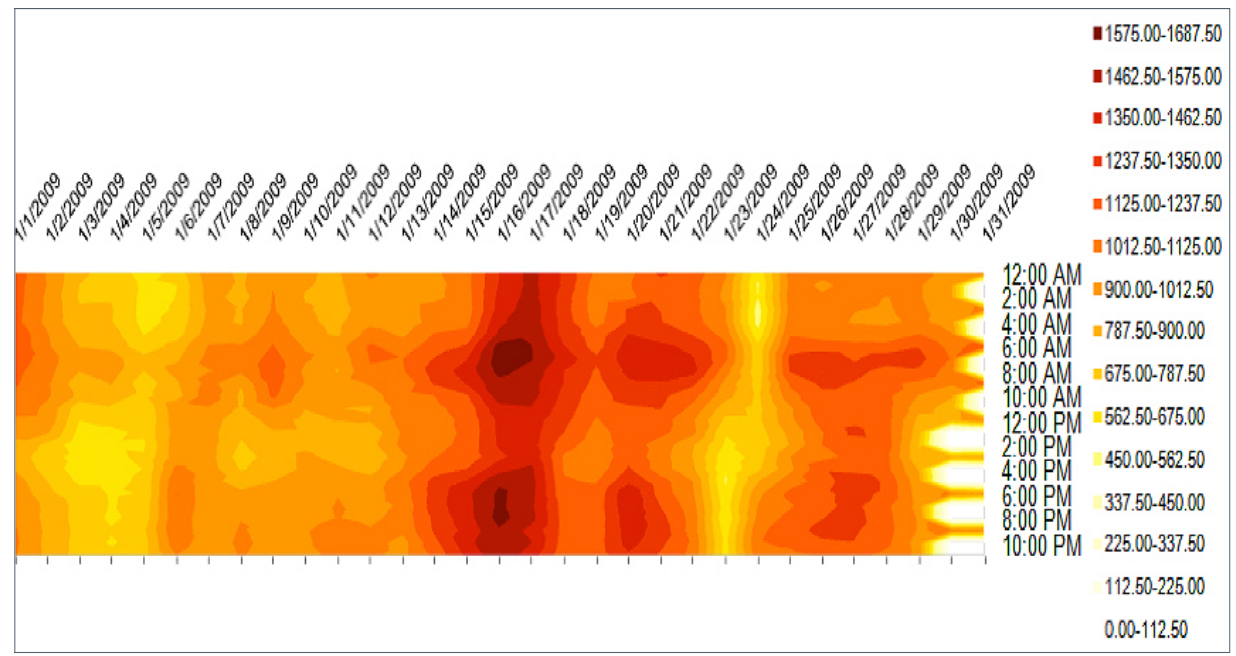

Figure 35: Energy Colors Chart Created from the Load Profile by Day Chart

\subsection{Load Profile Calendar}

The last item created from the Load Profile by Day chart is the Load Profile calendar, an example is shown in Figure 36. Unlike the previous two charts, the Load Profile calendar will not replace the Load Profile by Day chart. To view a different month on the calendar, however, you must re-create the calendar. If you simply change the MonthYr on the Load Profile by Day chart, the calendar will update, but the days will be incorrect. To view multiple months, it is again easier to create copies of the Load Profile by Day chart and choose different MonthYrs for each one, then create each calendar individually. 


\section{Load Profile as Box Plots}

This feature of ECAM is only available for Excel 2007 and 2010. Users of Excel 2003 will not be able to utilize this tool. This chart is created the same way as the "Point History Chart." Select the Load Profile as Box Plots option from the ECAM dropdown menu, and then select the whole building electricity consumption as the point of interest and hit OK. The chart will have the average consumption, median, and different percentiles of the data for the entire range of data, as shown in Figure 37. You can filter the data with the Pivot Table.

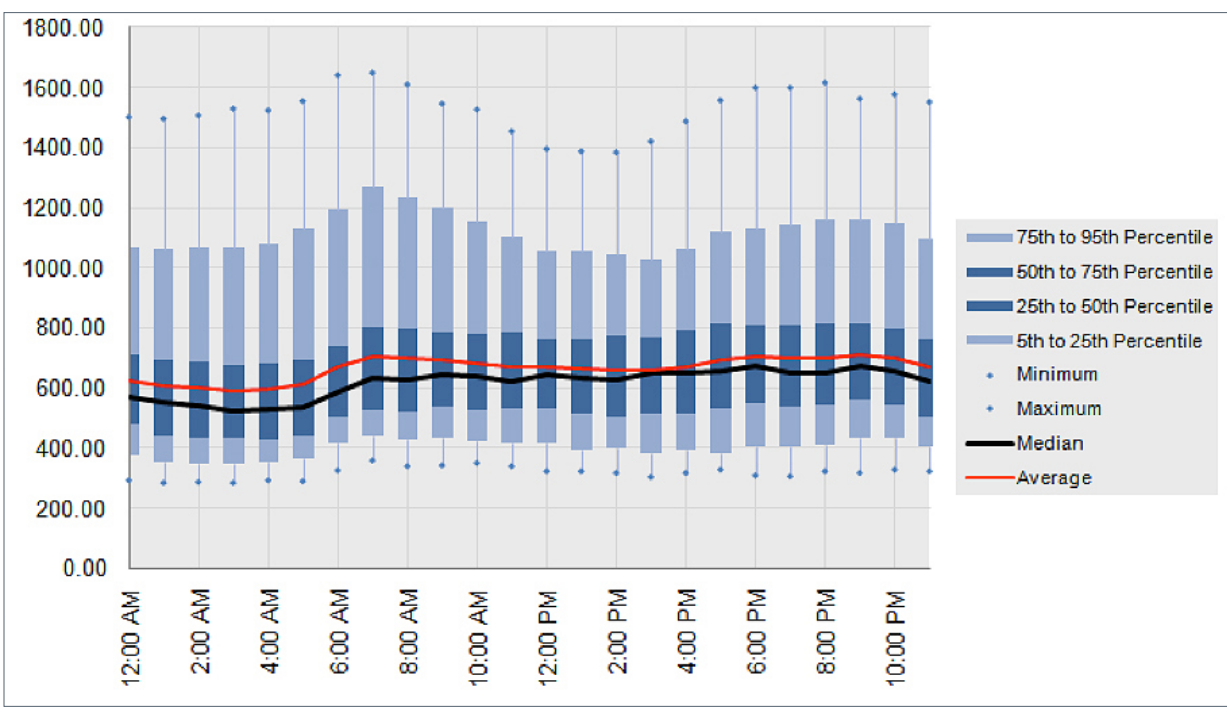

Figure 37 Load Profile as Box Plots Chart in ECAM

\section{Scatter Charts}

The next set of charts in ECAM are scatter charts. Scatter charts will only be useful if OAT is included in the data set because the scatter charts require this to be the independent variable ( $\mathrm{x}$-axis variable). A scatter chart can be created by occupancy or by date range per the dropdown menu in ECAM. The way these charts are created is slightly different. You must select the independent variable header first, and then hold down Ctrl and select the dependent variable(s).

\subsection{Scatter Chart by Occupancy}

This chart is very useful if a schedule was input into ECAM. Choosing this option plots two different lines; one for occupied hours, and one for unoccupied hours. If no schedule was input, all of the data will show as "Occupied," which is OK. Select the "Scatter Chart by Occupancy," and a window will come up like the one below (Figure 38).

Now you must choose the independent variable first, which in this case will be the OAT. Select the header, which will be something like Bldg1_Temp. Now, hold down $\mathrm{Ctrl}$ and select the dependent variable, or the whole building electricity consumption (ElecMtr1_kWh) and select OK.

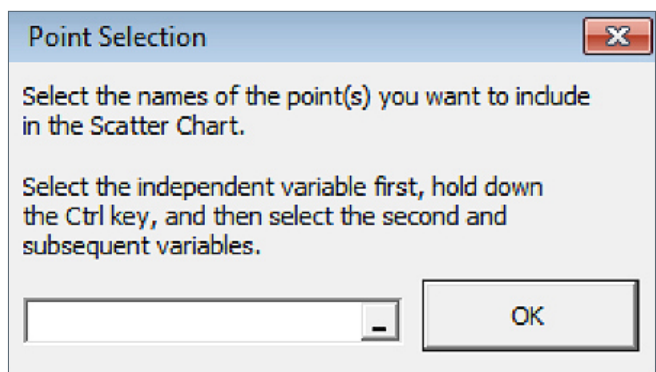

Figure 38: Point Selection Window for a Scatter Chart by Occupancy 


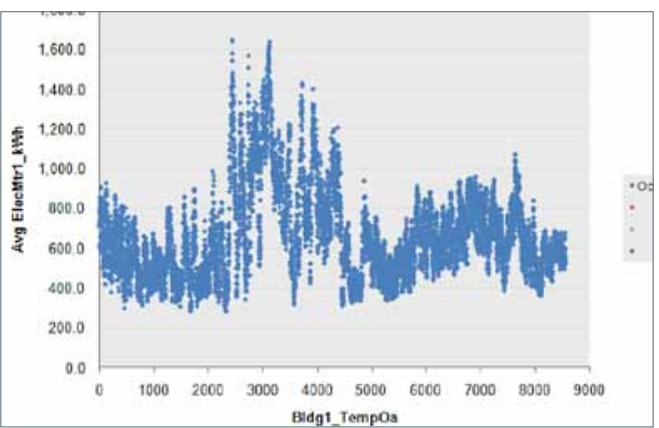

Figure 39: Scatter Chart by Occupancy With Errors.

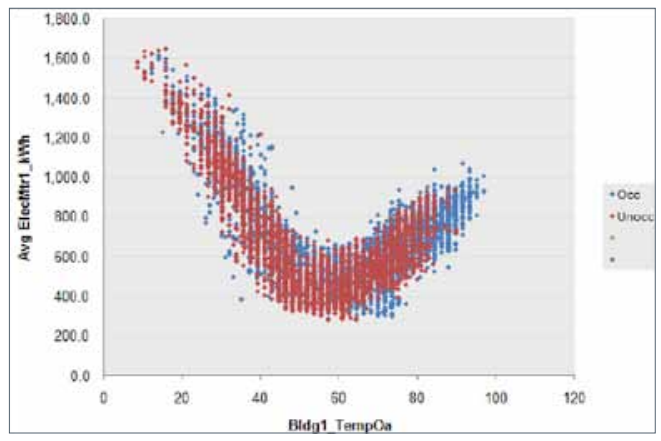

Figure 42: Scatter Chart by Occupancy in ECAM with a Schedule Input.
If there are any holes in the data, ECAM won't give the right chart here. The x-axis scaling won't look correct, like in Figure 39. To fix this, select the Bldg1_Temp dropdown menu from the Pivot Table, click on "blank," and then click OK. The chart should change to something more realistic (see Figure 40 and Figure 41). The legend on the right of the charts will have some blank values. The reason for these is because ECAM will plot 4 different things if they are available; occupied, unoccupied, equipment startup, and equipment shutdown.
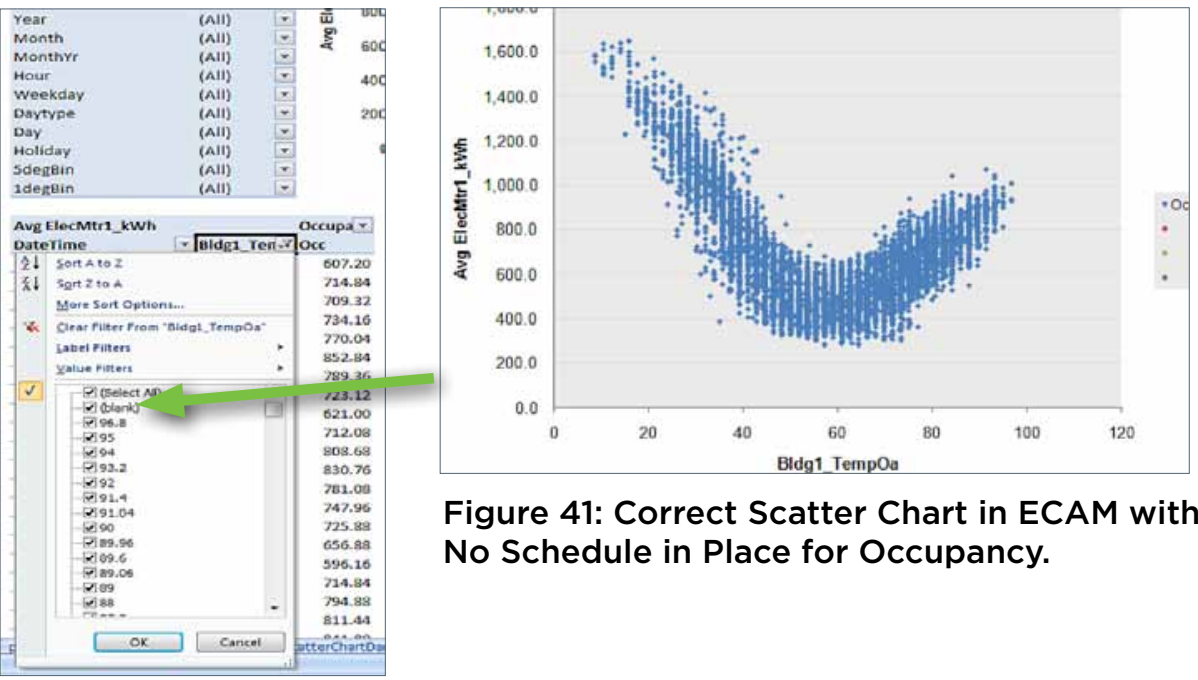

Figure 41: Correct Scatter Chart in ECAM with No Schedule in Place for Occupancy.

Figure 40: Removing the "Blank" Values from the OAT to get a Useful Chart

Now you will see that the $\mathrm{x}$-axis is correct, and this profile looks more appropriate for heating and cooling. The legend shows all blue points, or occupied. If you had put in a schedule, the chart may look something like Figure 42.

The last item under the Scatter Charts option in the ECAM dropdown menu is "Toggle Scatter Between all Time Stamps and Aggregated Values." This feature is useful for aggregating data and spotting trends. To do this, you must be in the Scatter Chart sheet. Select this option from the dropdown menu, and the chart will aggregate the data at each temperature bin; this cleans the data and makes it easier to trend, as shown in Figure 43.

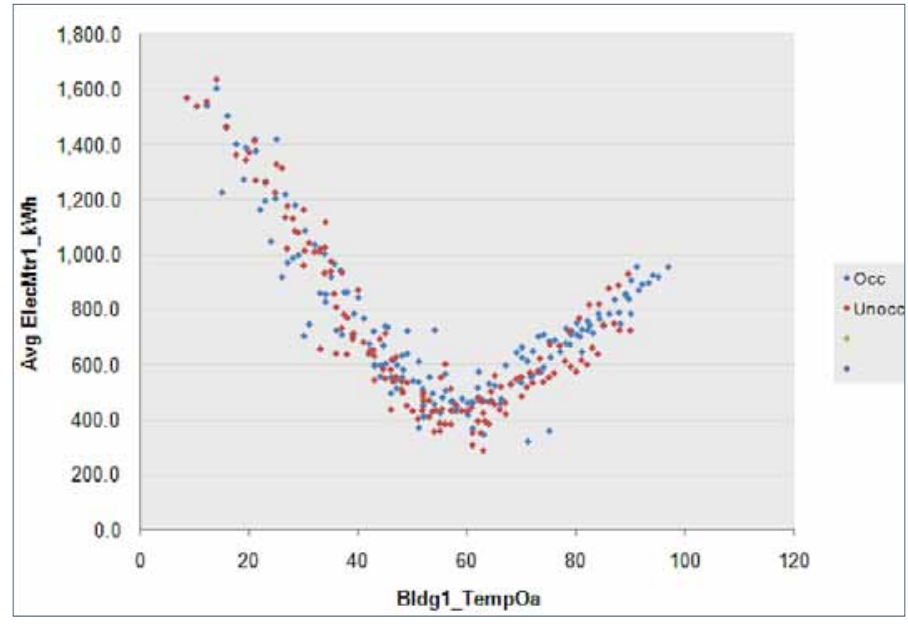

Figure 43: Scatter Chart Aggregated to Ppot Trends 


\subsection{Scatter Chart by Date Range (Pre-/Post-Retrofit)}

This scatter chart has the same objective as the prior one, but with regard to date ranges entered earlier in the process for comparison of pre- and post-retrofit. If dates were entered for retrofit or system modifications, this option will give up to three lines: before changes, during changes, and after changes. If no date range was input, you can still create this chart, but the title will show up "blank" because of no input dates. Figure 44 below shows an example of this chart for data starting in May 2008 and ending in October 2008. Utilizing the 4th item in the ECAM dropdown menu, "Input Dates for Comparison of Pre/Post," changes started to be made on 06/01/2008 and ended on 07/01/2008. See Chapter 3.5, Figure 18 and Figure 19 for inputting date ranges. After these dates were entered, under Scatter Charts in ECAM, select "Scatter Chart by Date Range (Pre/Post)," as in Figure 44.

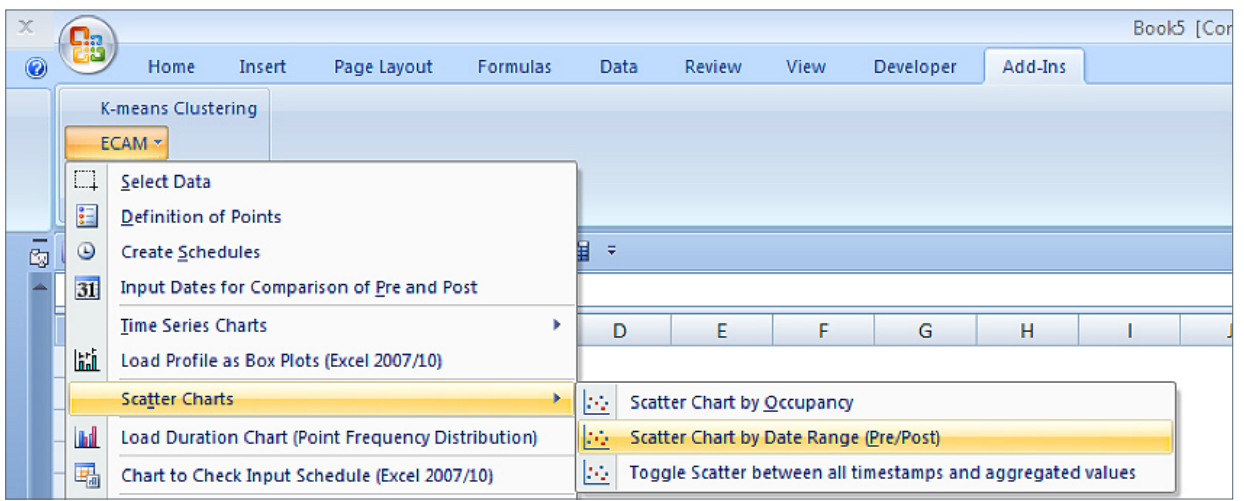

Figure 44: Creating a Scatter Chart by Date Range

After selecting this, ECAM will ask you to define the independent and dependent variable(s), as in Figure 45. Choose the OAT as the independent variable, and then hold down Ctrl and select the whole building electricity consumption, then click OK.

If you have any bad temperature values or missing time stamps, you may get a chart that looks something like the one depicted in Figure 46. To correct this, you must repeat the steps discussed in Figure 39 through Figure 41. Once you correct the missing data, the correct chart will look something like Figure 47.

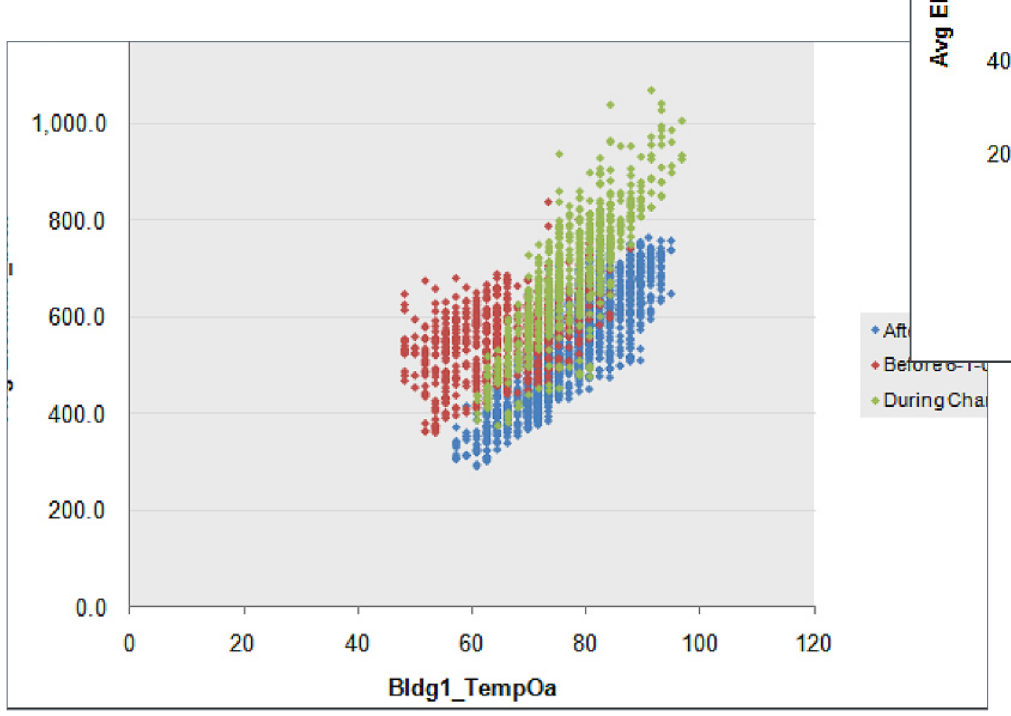

Figure 47: Correct Scatter Chart by Date Range

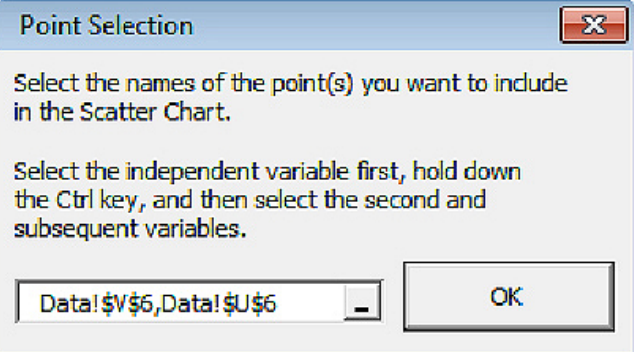

Figure 45: Point Selection for Scatter Chart by Date Range 


\section{Interval Metered Data Analysis}

Interval data can provide useful and actionable information by careful review of the data. As described in the previous section, a number of charts can be created using interval metered data. In this section, using example charts we show what to look for.

\subsection{Weekday/Weekend Scheduling and Occupancy}

Utilizing the Load Profile by Daytype and 3d plots in ECAM, electricity consumption patterns can be analyzed and actionable information generated. For example, Figure 48 shows a Load Profile by Daytype created in ECAM. Three key things can be spotted from this chart. In a typical building with 10 to 12 occupied hours, the nighttime consumption should be about $20 \%$ to $30 \%$ of the day peak consumption (occupied vs. unoccupied hours consumption). From this chart (Figure 48), during unoccupied hours, the consumption is roughly $200 \mathrm{kWh}$, and during the occupied hours, roughly $350 \mathrm{kWh}$. This is about a $40 \%$ reduction in consumption, which indicates that some equipment or plug loads are probably $\mathrm{ON}$ during unoccupied hours. Further investigation of the loads through a building walkdown can yield actionable information to lower the nighttime electricity consumption.

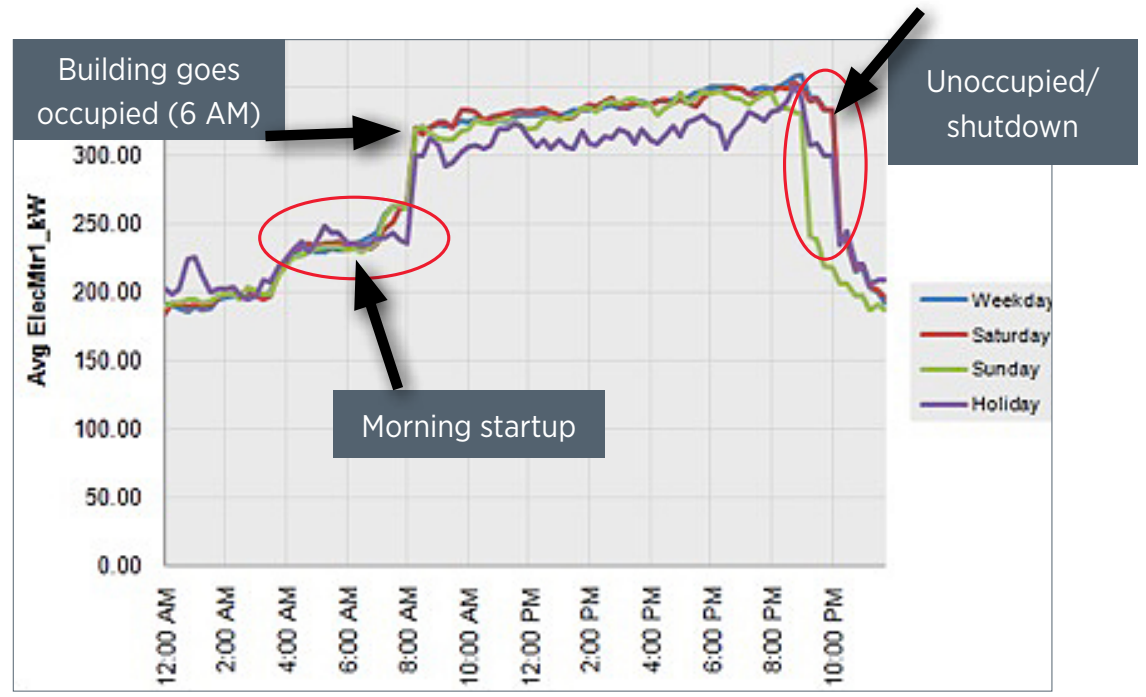

Figure 48: Load Profile by Daytype

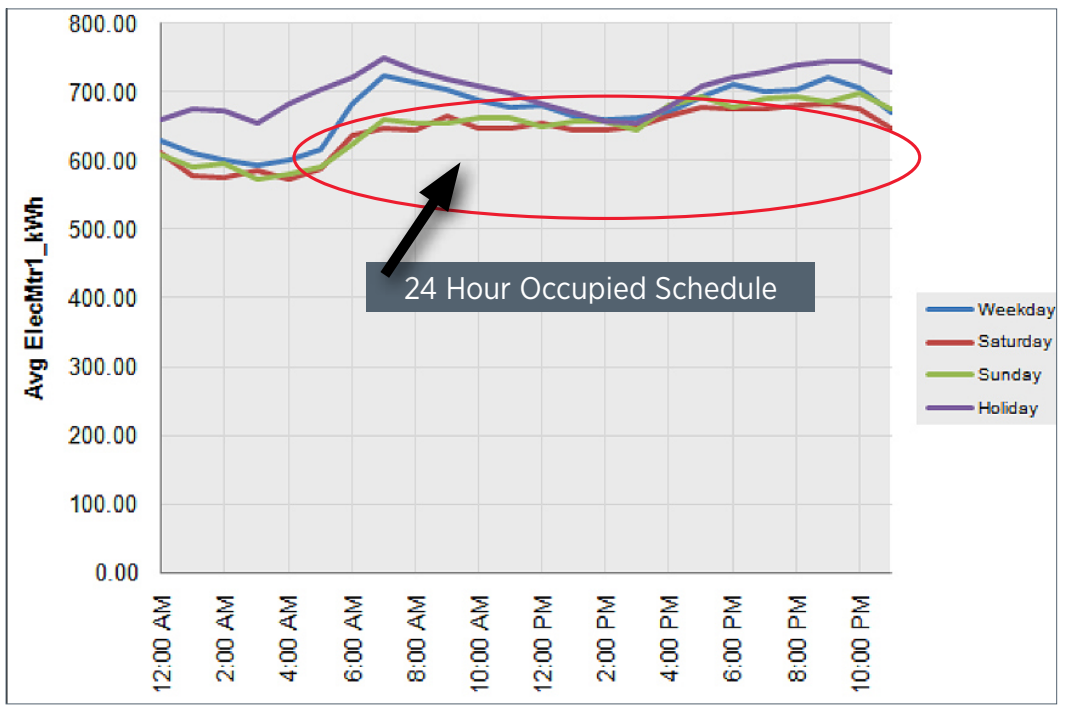

Figure 49: Typical Load Profile by Daytype for Hospital or Hotel
Figure 48 also shows that this building appears to begin occupancy between 7 AM and 8 AM every day of the week and shutting down at 10 PM Monday through Saturday, and 9 PM on Sunday. If this were an office building, and if most people leave the building between 5 PM and 6 PM, there appears to be significant consumption between 6 PM and 10 PM, which may provide opportunities for reductions of electricity consumption during unoccupied hours.

The building also appears to have no holiday schedule because the consumption on holidays appears to be same as a weekday operation. By employing a separate holiday schedule, additional electricity reductions are possible. Figure 49 shows a consumption profile for a building that appears to be occupied 24 hours a day, 7 days a week (hospital or hotel building types). 
Figure 50 shows load profile by daytype for an office building. This building appears to be occupied 5 days a week, like a typical office building. The building appears to be occupied starting at around 6 AM and appears to go unoccupied around 4 PM. However, unlike the startup period in the morning, the shutdown period appears too long. If the long shutdown period is not expected, a building walkdown after 6 PM will show equipment and plug loads that are $\mathrm{ON}$ during that time. Furthermore, the nighttime consumption is $50 \%$ of the peak consumption, indicating that significant loads are still $\mathrm{ON}$ during the unoccupied period.

Figure 51 shows a typical office building that is properly run. This building has a 6 AM to 6 PM 5-day schedule and is unoccupied on the weekends. The nighttime consumption is only about $20 \%$ of the peak consumption during occupied hours.

\subsection{Pre/Post Load Profile by Date Range}

If a building undergoes a major retrofit or retro-commissioning, ECAM's Load Profile by Date Range (Pre/ Post) can be used to see what kind of reduction in energy has occurred in the building. Figure 52 shows the red line as the profile before retrofit or retrocommissioning, the green line as the profile during the changes, and the blue line as the profile after the retrofit or retro-commissioning has taken place. The important changes to notice are the following: The peak consumption before retrofit was around $120 \mathrm{kWh}$, and after retrofit it dropped to around $100 \mathrm{kWh}$. The startup and shutdown schedule was tightened so that the equipment was starting up and shutting down faster, and the building unoccupied percent of peak demand was also lowered from $50 \%$ of peak to $20 \%$ of peak. The area between the blue and red lines is the amount of energy saved per day for this building.

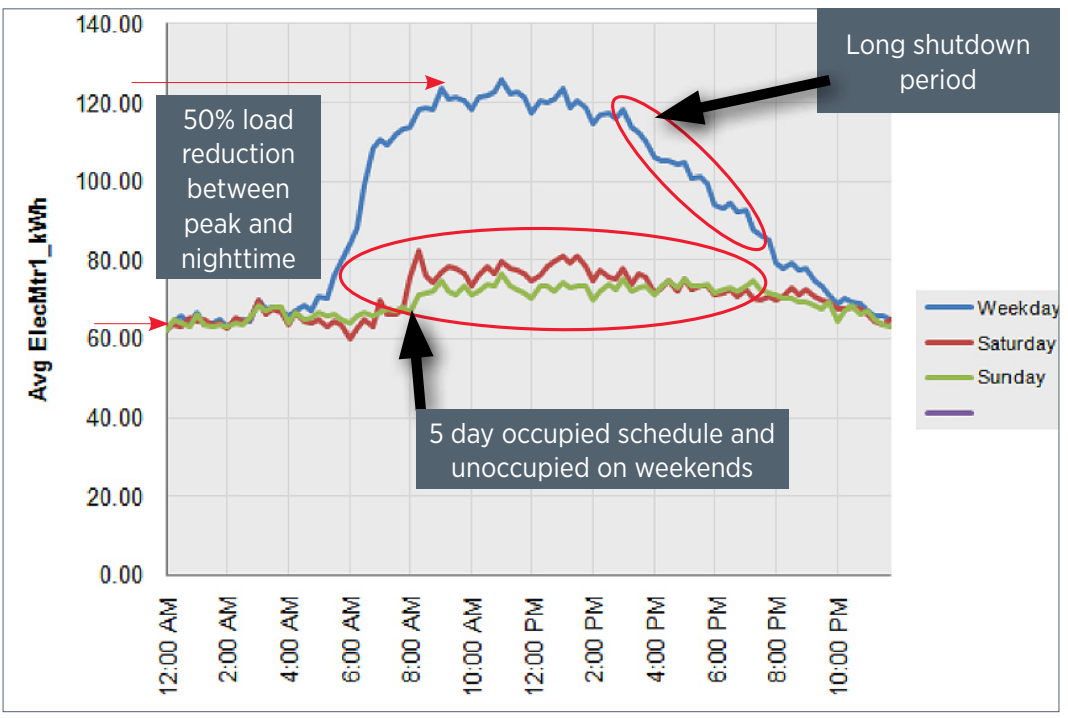

Figure 50: Typical Office Building Load Profile by Daytype

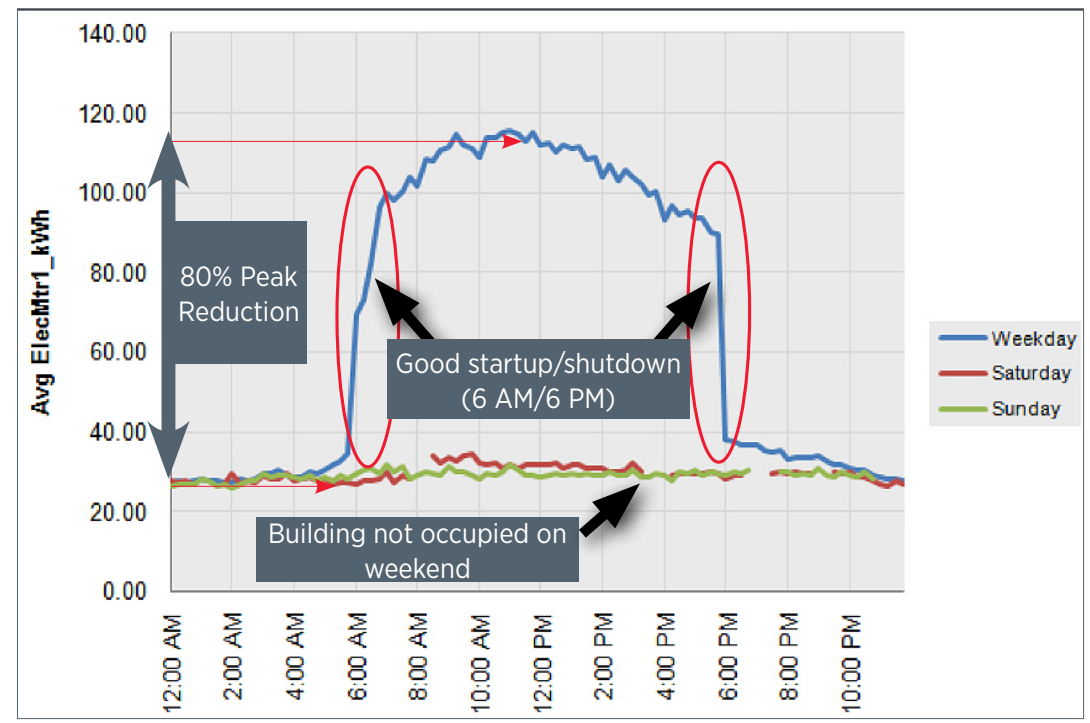

Figure 51: Office Building that is Well Controlled and Operated

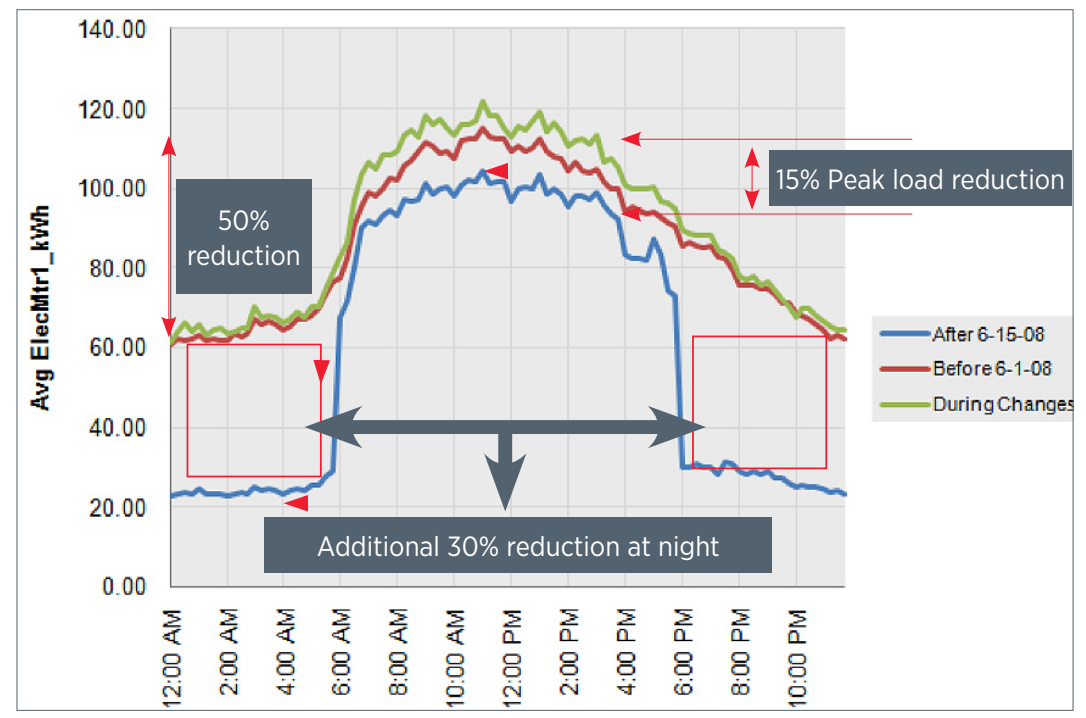

Figure 52: Office Building Load Profile Comparison Before and After Retrofit or Retro-Commissioning 


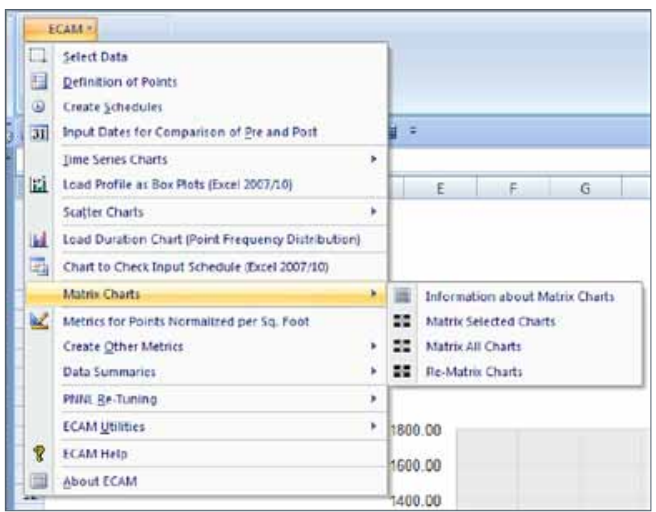

Figure 53: Matrix Charts Dropdown Menu

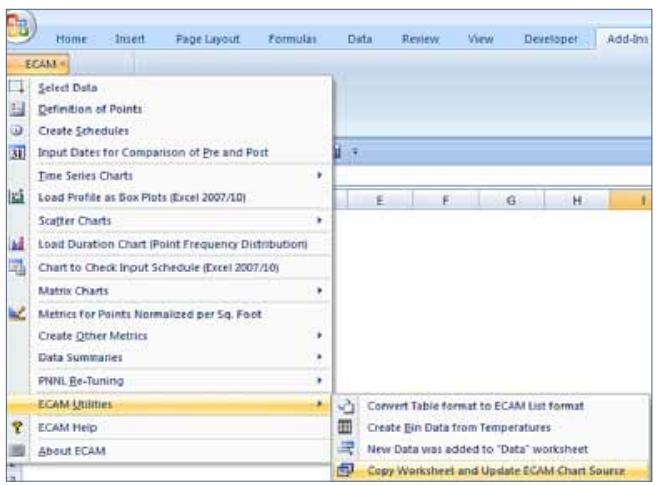

Figure 54: ECAM Utilities to Copy Worksheet and Update ECAM Chart Source

\section{Advanced ECAM Capabilities \\ 8.1 Matrix Charts Option}

Another useful tool in ECAM is the matrix charts option as seen in the dropdown menu (Figure 53). The top selection gives some basic information about what the matrix charts option provides, then there are three options below that: matrix selected charts, matrix all charts, and re-matrix charts. The matrix selected charts gives the user the ability to select whatever charts they want and place them all in the same page for comparison purposes. The matrix all charts takes every chart created in the workbook and places them in the same sheet for comparison. To demonstrate this, consider the Point History Charts discussed in Chapter 4.1. The first step is to create the point history if not already created. You can select a specific month, week, or day. Once the chart is done, use the ECAM utilities shown in Figure 54 to "Copy Worksheet and Update ECAM Chart Source." This will make an exact copy of the worksheet, and keep the Pivot Table linked to the data. Now you can change the filter to the next month, week, or day. You will also want to rename the worksheet, because ECAM will make the new sheet the same name as the old sheet, but add a (2) to it. It is always a good idea to name each sheet to your own preference to remember what charts have been created.

This method can be repeated for each month, week, or day until all charts of interest have been created. At this time, you can use the ECAM tool, "Matrix Selected Charts." Now you must hold down the Ctrl key and select each Point History Chart that you want included in the matrix charts BEFORE you click the Matrix Selected Charts option. If you click it without highlighting any charts, it will show up as a blank sheet. Figure 55 shows an example of Point History Charts matrixed together.

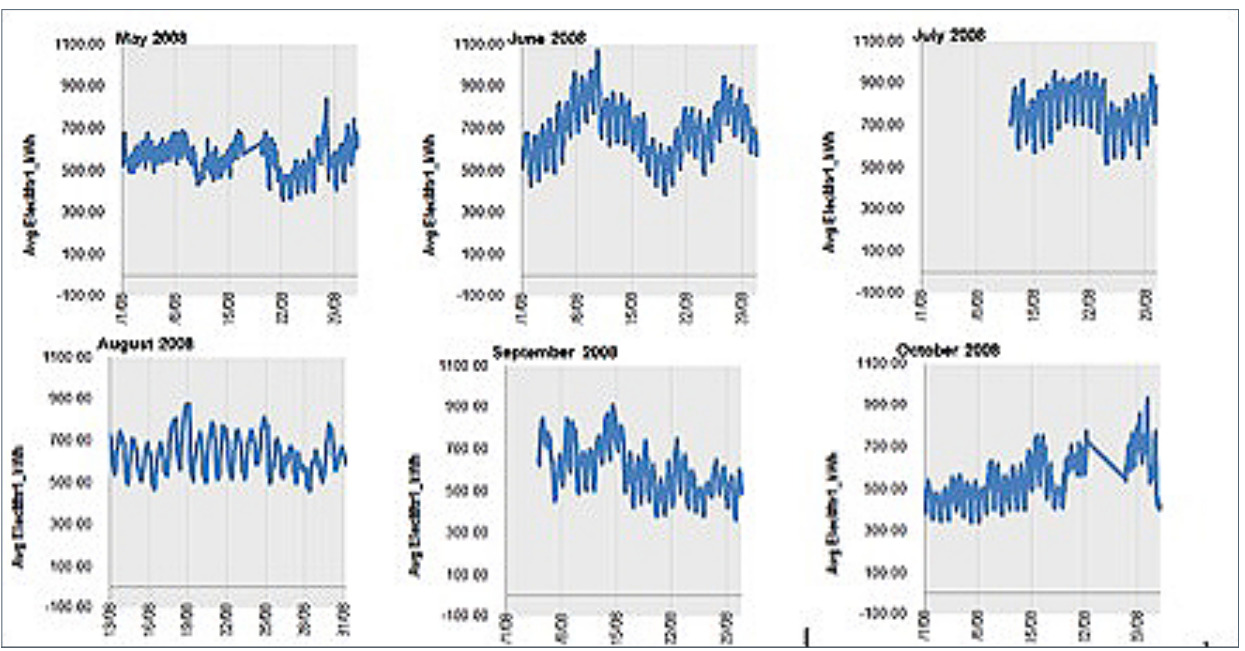

Figure 55: Point History Charts Side by Side via the Matrix Selected Charts Option in ECAM

Some editing may be required before matrixing charts. For example, titles may have to be added manually, axis shrunk or even deleted because of sizing, etc. Shrinking charts sometimes makes the data difficult to see, so minimizing other things is necessary. 


\section{Appendix A}

\section{ECAM Installation}




\section{Appendix A: ECAM Installation}

This tool was developed using Excel 2007 and 2010, and has had some testing to confirm it still works with Excel 2003. It has not been tested on earlier versions. A couple of the new charts will only work with Excel 2007 and 2010.

The system requires continuous, uniform interval data. Change-of-value data, or data with different parameters stored at different time intervals, must be pre-processed. One tool designed to assist and automate such pre-processing is the Universal Translator, available at www.utonline.org.

The basic charting of a data history will work fine on non-uniform time intervals, but multiple points would still need to have the same time stamps.

\section{Installation}

The energy charting and metrics tool is installed as an Excel Add-In. Save the tool file in your chosen location. Please note that Microsoft Add-Ins are installed, by default, in a common location, such as Documents and Settings. It can, however, be saved to any location.

To install the application, open Excel and perform the following steps:

\section{Excel 2003:}

Go to Tools, Add-Ins, and Browse to the location where the file was saved. Select the filename, and click OK. "ECAM" will be in the list of Add-Ins. There will also be a Menu called ECAM in the Excel Toolbar.

\section{Excel 2007/2010:}

Click on the Office Button, and then click "Excel Options." Click on "Add-Ins" on the left side of the window. At the bottom of the subsequent window, make sure that "Excel Add-Ins" is visible in the drop-down next to "Manage." Click the adjacent "Go..." button. Then Browse to the location where the file was saved. Select the filename, and click OK. "ECAM" will be in the list of Add-Ins. An ECAM menu will be available under the Add-Ins menu. This update of ECAM does not include a Ribbon for ECAM. 
